\title{
A SPATIAL MODEL FOR THE SPREAD OF INFLUENZA WITHIN THE HUMAN RESPIRATORY TRACT
}

\author{
by \\ Nada P. Younis \\ B.Sc. Physics, Beirut Arab University, Beirut, Lebanon, 2009
}

\author{
A thesis \\ presented to Ryerson University \\ in partial fulfillment of the \\ requirements for the degree of \\ Master of Science \\ in the Program of \\ Biomedical Physics
}

Toronto, Ontario, Canada, 2012

(c) Nada P. Younis 2012 


\section{Author's Declaration}

I hereby declare that I am the sole author of this thesis. This is a true copy of the thesis, including any required final revisions, as accepted by my examiners.

I authorize Ryerson University to lend this thesis to other institutions or individuals for the purpose of scholarly research.

I further authorize Ryerson University to reproduce this thesis by photocopying or by other means, in total or in part, at the request of other institutions or individuals for the purpose of scholarly research.

I understand that my thesis may be made electronically available to the public for the purpose of scholarly research only. 


\begin{abstract}
A spatial model for the spread of influenza within the human respiratory tract

\author{
Nada P. Younis \\ Master of Science, Biomedical Physics
}

Ryerson University, 2012
\end{abstract}

Several mathematical models with varying degrees of complexity are dedicated to characterizing influenza virus infection kinetics. The majority of existing mathematical models of in-host kinetics are based on ordinary differential equations (ODEs) and do not incorporate viral transport modes. In this work, a spatial model was developed in order to explore, for the first time, the effect of viral transport modes in-vivo: diffusion and advection. Cellular regeneration and a simplified immune response were also included in this model. Although severe and chronic infections sometimes occur in humans, most of the existing models can only reproduce seasonal infections. This new model has successfully reproduced observed infection profiles within realistic biological parameters. The changes in parameters required to shift the infection kinetics from a seasonal to a chronic infection, for example, is consistent with the factors believed to be responsible for the establishment of such infections. 


\section{Acknowledgements}

I would like to thank everyone at Ryerson University who contributed to my work during the past two years. First I thank my supervisor Dr. Catherine Beauchemin for her active supervision and inspiring discussions in directing my research project. I would also like to thank my supervisory committee members Dr. Emily Heath and Dr. Tim Sly for following up with my project progress, and Dr. Karshafian for making my last supervisory meeting possible. I thank Dr. Kumaradas who agreed to sit on my examination committee. I would like to acknowledge Dr. Benjamin Holder and Dr. Hana Dobrovolny for helpful discussions and all the support they provided throughout my project. I would also like to acknowledge all the faculty and staff here at Ryerson University for their help in different aspects. I would also like to acknowledge the Natural Sciences and Engineering Research Council for providing funding for this work, and Ryerson University for financial assistance, and the facilities of the Shared Hierarchical Academic Research Computing Network (SHARCNET:www.sharcnet.ca) and Compute/Calcul Canada without which this work would have been impossible to complete.

I would like to thank all of my family members and friends who have supported me morally and my husband who was always by my side. 
To the one whose unconditional love has been my motivation for years and years now, but chose to remain unknown. 


\section{Table of Contents}

1 Introduction 1

1.1 Infection milieu $\ldots \ldots \ldots \ldots \ldots$

1.2 Infection dynamics . . . . . . . . . . . . . . . . . . . 4

1.3 Immune response induced against influenza infections $\ldots \ldots \ldots \ldots$

1.3.1 Innate immunity . . . . . . . . . . . . . . . 7

1.3.2 Adaptive immunity . . . . . . . . . . . . . . . 8

1.4 Motivation .............................. 9

2 Methods 12

2.1 Mathematical model . . . . . . . . . . . . . . . . . . . . 12

2.2 Parameter estimates . . . . . . . . . . . . . . . . . . 13

2.3 From zero-dimensional to 1 -d formulation . . . . . . . . . . . . . 14

2.4 Numerical formulation . . . . . . . . . . . . . . . . 15

3 Viral transport modes $\quad 18$

3.1 Virus diffusion in the periciliary fluid . . . . . . . . . . . 18

3.2 Virus entrainment in the mucosal elevator and a threshold for infection . 20

4 Respiratory tract epithelium regeneration and chronic infections 22

4.1 Density-independent regeneration . . . . . . . . . . . . . . . . . . . 22

4.2 Density-dependent regeneration . . . . . . . . . . . . . . . . 26 
6 Innate and adaptive immune responses and the resolution of infection 31

6.1 Interferon . . . . . . . . . . . . . . . . . . . 32

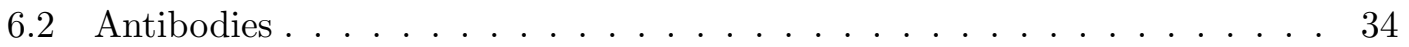

6.3 Reproducing the three infection profiles . . . . . . . . . . . . 39

$\begin{array}{lll}7 & \text { Discussion } & 41\end{array}$

$\begin{array}{ll}\text { Bibliography } & 43\end{array}$

$\begin{array}{ll}\text { Glossary } & 52\end{array}$ 


\section{List of Tables}

2.1 Default initial conditions and parameter values of the target cell limited model. . . . . . . . . . . . . . . . . . . . . 14

6.1 Estimates of antibody clearance in mathematical models. . . . . . . . . . 37 


\section{List of Figures}

1.1 Infection milieu of within-host influenza infection. . . . . . . . . . . . 3

1.2 Influenza viral replication cycle. . . . . . . . . . . . . . 5

1.3 The three types of influenza infections. . . . . . . . . . . . . 6

1.4 Sample interferon time courses in humans and animals and their effect on viral titer in mice. . . . . . . . . . . . . . . 8

1.5 Sample antibody time courses in mice and their effect on viral titer in mice. 9

3.1 The effect of varying the rate of viral diffusion. . . . . . . . . . . . . 19

3.2 The effect of changing production on infection kinetics in the presence of both advection and diffusion. . . . . . . . . . . . . 21

3.3 Early infection spatial profile. . . . . . . . . . . . . . . . 21

4.1 The algorithm utilized in reducing the size of the stored dead cells matrix. 24

4.2 Exploring infection dynamics in the density-independent target cell regeneration model. . . . . . . . . . . . . . . . . . 25

4.3 Exploring infection dynamics in the density-dependent target cell regeneration model. . . . . . . . . . . . . . . . . . 27

5.1 The effect of changing the depth of deposition. . . . . . . . . . . 30

6.1 The time courses of IFN . . . . . . . . . . . . . . . . . . . 32

6.2 The effect of interferon on infection kinetics. . . . . . . . . . . . . . 33

6.3 The effect of changing the time of IFN peak on infection kinetics. . . . . . 35

6.4 The time courses of Ab. . . . . . . . . . . . . 36

6.5 The effect of initial Ab abundance on the infection kinetics. . . . . . . . . 37

6.6 The effect of $\mathrm{Ab}$ on the infection kinetics. . . . . . . . . . . . . 38

6.7 Exploring the effect of preexisting immunity on the infection kinetics. . . 39

6.8 The three infection profiles observed in patients. . . . . . . . . . . . 40 


\section{Chapter 1}

\section{Introduction}

Influenza is an infectious disease that affects between 3-5 million people annually causing 250,000-500,000 deaths [83]. Due to the financial burden on the workforce and health care system caused by seasonal infections, studying and understanding influenza virus kinetics in humans is very important for proper treatment planning and pandemic preparedness.

While experimental studies are key for the proper understanding of influenza, even more information can be extracted from them when aided by quantitative models. Mathematical and computational modelling was previously used in characterizing other infectious viruses. With the aid of mathematical models, subtype differences and treatment efficacy were determined for hepatitis C virus (HCV) $[20,55,56]$; virion half life, production rate, infectious cell lifespan, and treatment kinetics were estimated for the human immunodeficiency virus (HIV) as well as for the influenza A virus $[2,12,22,35,59,60]$. Thus, mathematical modelling has proved to be successful in quantifying the parameters governing infection and in improving our understanding of infectious disease kinetics.

Increasing interest in using these tools to complement experimental data on influenza led to the development of numerous mathematical and computational models. The mathematical models of influenza are mainly based on ordinary or delay differential equations (ODEs) that describe the temporal evolution of infection $[2,12,21,30,31,47$, $53,67]$ with implicit well-mixed system assumptions, this means in the case of infectious disease kinetics that the various cell populations and virus are uniformly distributed over space [6]. For example, the study of cell tropism, i.e. certain host cell types being selectively subject to infection by a certain viral strain, by Dobrovolny et al. assumes that both cell types are equally accessible to virus [21], whereas known histology suggests a variation in cell type distribution, size, density, and tropism in the different parts of 
the respiratory tract $[16,52,57,69,73,77,85]$.

Another approach is to use agent-based models which treat the dynamics of each cell individually $[7,8,75]$. However, these models are computationally intensive and complicated, as they include a large number of interacting components and mechanisms, which hampers the interpretation of simulation results [4,9]. More recently, attempts at using partial differential equations (PDEs) to study infection kinetics have started. For example, Holder et al. studied influenza kinetics in a two-dimensional cell culture and provided insights into spatial and temporal evolution of infection dynamics and assessed the in vitro fitness of a viral strain by estimating its viral production rate, duration between infection and viral production and time required by freshly produced virions to infect susceptible cells [38].

\subsection{Infection milieu}

The respiratory tract is made up of three regions: the extra thoracic region made up of the nasal passage, larynx and pharynx; the tracheobronchial region made up of the trachea, bronchi, bronchioles and terminal bronchioles; the alveolar region made up of respiratory bronchioles and alveolar ducts and sacs surrounded by alveoli. The alveolar region is responsible for the respiratory gas exchanges at the level of individual alveoli, whereas the other two regions are conducting regions only. The trachea is a cylindrical tube referred to as the first generation. Its bifurcation into the main bronchi forms the second generation which further bifurcate into the third generation and so on till the $25^{\text {th }}$ generation at the alveoli [36].

The respiratory epithelium consists of more than 40 different cell types classified into 4 main types: ciliated cells, non-ciliated cells, Clara cells and basal cells. They are distributed in a monolayer, called the epithelium, everywhere except in the trachea [62]. Several studies have shown that the cells susceptible to influenza infection are the ciliated and non-ciliated cells with varying degrees of susceptibility depending on the origin of the viral strain $[49,50,57,77,85]$. The involvement of two different cell types in infection dynamics is a possible contributor to infection severity by some strains [21]. Influenza virus exists in many strains that can infect different animal species besides humans, and each strain is adapted to its host species. Infections due to human-adapted strains are known to cause pathology predominantly, but not exclusively, localized in the upper part of the respiratory tract (trachea and bronchi), whereas avian-adapted strains predominantly, but not exclusively, cause pathology in the lower respiratory tract (bronchioles and alveoli), particularly in the alveolar region [46]. It is not clear weather the 


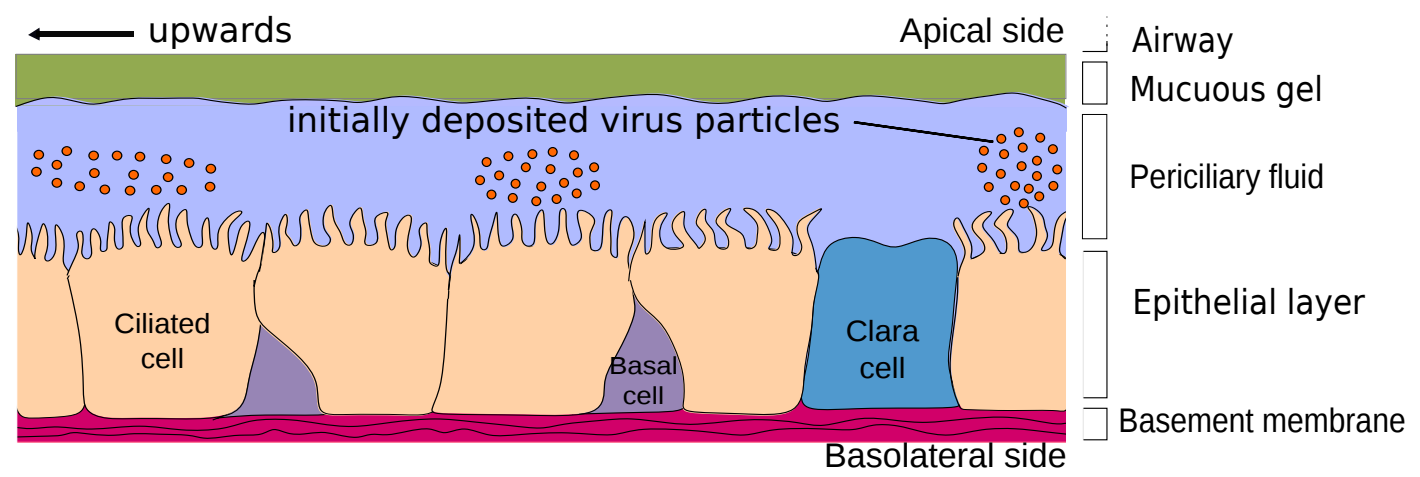

Figure 1.1: Infection milieu of within-host influenza infection. The four main cell type classes are Clara, basal, ciliated and non-ciliated cells. The cells are covered by a thin layer of PCF, virus present in this layer can infect epithelial cells while it diffuses uniformly and moves upwards driven by the mucosal escalator. Figure modified from [5].

selective prevalence of influenza strains in different parts of the respiratory tract is due to cell tropism or due to the depth of deposition of these two types of virus. Typically, human influenza is transmitted from coughed droplets from an infected individual, whereas avian influenza is transmitted from infected birds. This may affect the depth of deposition.

The epithelium is covered by a layer of fluid called the periciliary fluid (PCF) whose height is about $6 \mu \mathrm{m}$ followed by a mucus layer whose height is approximately $25 \mu \mathrm{m}$. Fig. 1.1 shows the epithelial monolayer of cells covered by layers of periciliary fluid and mucus. The mucus layer moves upwards driven by ciliary propulsions at a speed that ranges between $13-213 \mu \mathrm{m} \cdot \mathrm{s}^{-1}[11,51,82,86]$. It serves as a protection against foreign pathogens by trapping and transporting them outside the respiratory tract. Mucus binds influenza virions via sialic acid receptors [3]. Due to cilia propulsion and mixing between the mucus and PCF layers the latter was found to be driven upwards by the mucus at an equal speed $[51,70]$. This means that any virus particles found in the PCF will be transported upwards and away from the lower parts of the respiratory tract. Additionally, virions diffuse within the PCF.

Resting epithelium is characterized by a slow turnover rate. However, in case of injury to the tracheal and bronchial epithelium, such as a viral infection or bacterial infection, exposure to an oxidizing agent, or mechanical damage, a common, rigorous and complex, regeneration process is triggered within $0-1$ day post injury $[15,80]$. Differentiated cells such as ciliated cells do not divide directly. Instead, they first de-differentiate, then spread to cover the wound and replicate. Basal cells also migrate to the site of injury, 
divide and differentiate into the different cell types until the epithelium is restored to its initial, uninjured, state. In a study involving healthy humans, regions $0.8-2 \mathrm{~cm}$ in diameter, located in the second and third generation bronchi were denuded by brushing. As determined by bronchoscopy and study with real time polymerase chain reaction detecting and quantifying gene expression, the epithelium was restored into a very similar state to its resting condition approximately by 14 days post-injury [18,34]. Clara cells are believed to be among the progenitor cells in the bronchi, and alveolar type II cells are precursors for alveolar cells of type I and II. The full picture of epithelial regeneration and progenitor-progeny relationships is a subject of current scientific investigation [78].

\subsection{Infection dynamics}

Infection is initiated by virions that cross the mucus barrier and proceed to infect susceptible cells in the respiratory tract. Virions are absorbed into the cells through endocytosis approximately 20 min post-infection after they attach to cell receptors through their surface proteins called hemagglutinins [62]. Viral genetic material is unpacked inside the cell and transported to the cell nucleus. The virus takes control over the cell's replication machinery to make copies of the viral genome and to produce viral proteins. The viral proteins, along with the virus' genetic material, are assembled within the cell and then released outside the cell by a process called "apical budding", and the cell surface bears viral proteins and forms newly released virions' membrane. A schematic illustration of viral replication cycle is shown in Fig. 1.2. The delay between virus entry into the cell and viral release to infect other cells is called the eclipse phase, and is estimated to be about $6 \mathrm{~h} \mathrm{[2]}$. The infectious cell will continue to produce virions until it dies when its membrane is consumed or gets killed by the host immune response after 12-24 h $[2,12]$.

For uncomplicated influenza infection, viral titer grows rapidly and peaks $2-3$ days post-infection (dpi), and is cleared $6-8$ dpi $[2,12,62,84]$. Cell death accompanies the infection, and at the peak of infection $30-50 \%$ of these cells are destroyed. Clinical symptoms are typically observed once approximately $10 \%$ of the epithelium in the upper airways has been desquamated [12].

Clinical symptoms of influenza are caused by cell death as well as the immune response. They include a sudden onset of high fever, headache, muscle and joint pain, dry cough, severe malaise (feeling unwell), sore throat and runny nose [83]. Symptoms usually manifest themselves starting from 1-2 dpi for human-derived strains and disappear around 5-6 dpi [26,33] without any medical intervention in most cases [83].

Sometimes, in the case where the host encounters a pandemic strain with increased 


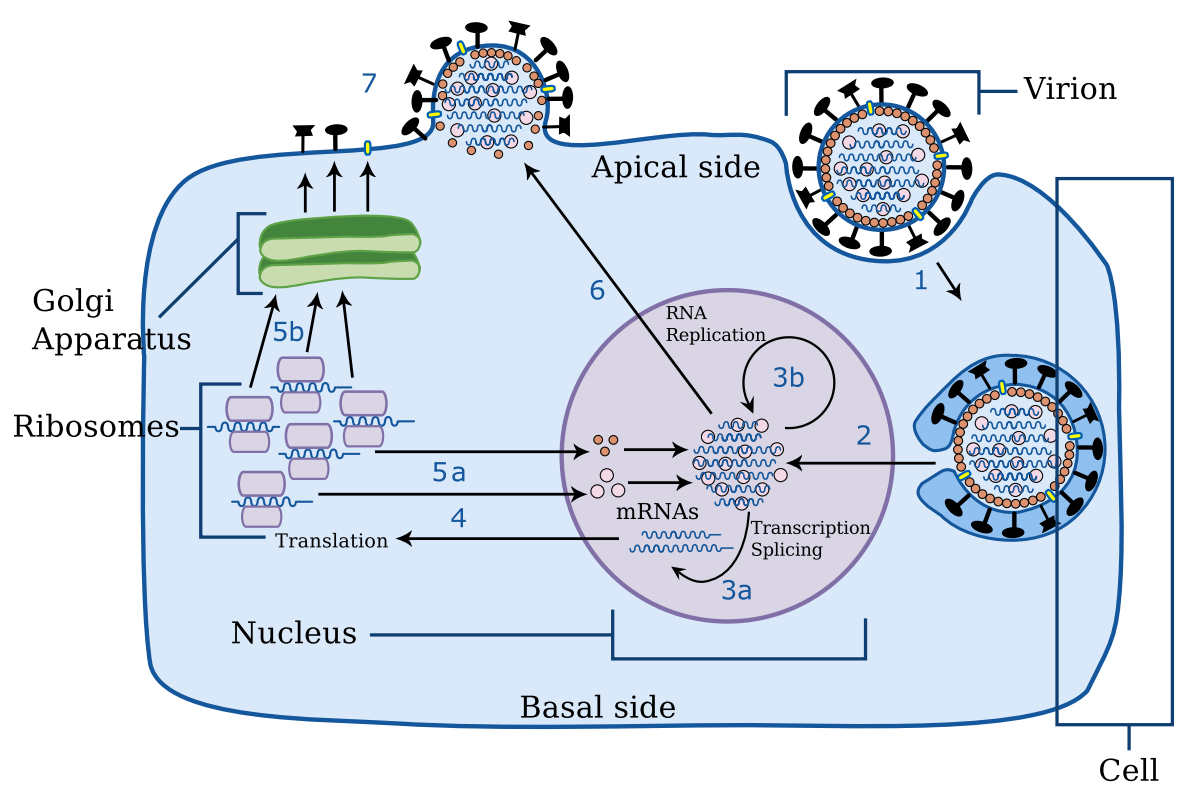

Figure 1.2: Influenza viral replication cycle.. The virus invades the cell through its hemagglutinin, once inside it unpacks its viral genome which is then transported into the nucleus. Copies of the viral genome are made and translated into viral proteins which, once assembled into virions, are released outside the cell by apical budding. Viral proteins are now expressed on the cells surface. Figure from the Wikimedia artwork called "Virus Replication large.svg" modified by Dr. Catherine Beauchemin. 

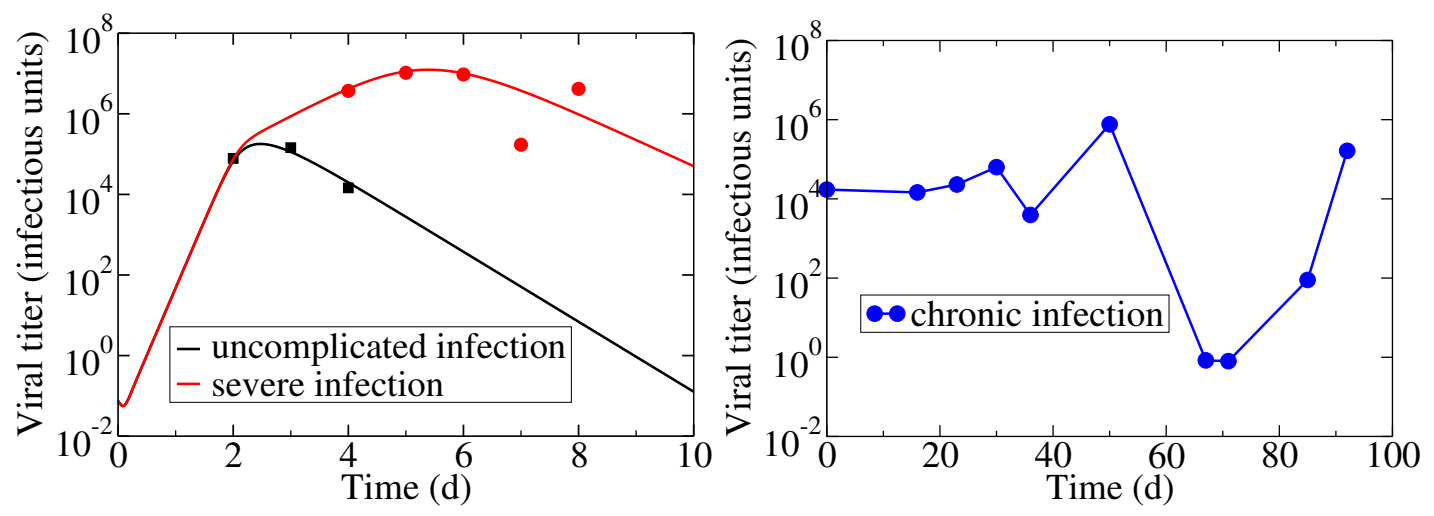

Figure 1.3: The three types of influenza infections. Left panel shows viral titers characteristic of acute seasonal and severe infections adapted on a time scale up to 10 days post infection, figure is a courtesy from Dr. Hana Dobrovolny. The right panel shows the profile for a chronic infection on a time scale up to 100 days post infection adapted from [65].

severity, infection may be accompanied by high viral loads, and lasts longer until the host's immune response effectively clears the pathogen. An immunocompromised patient, however may be unable to clear the infection without treatment. The resulting infection is characterized by a high and sustained viral titer ${ }^{1}$ that can last up to months. The general picture for the viral kinetics over the course of these three types of infection observed in patients are shown in Fig. 1.3.

The immune response against influenza virus plays an important role in shaping the infection. In most cases of infection with a human adapted influenza, immune response resolves the infection into an uncomplicated, seasonal, form within around one week of infection. In case of more severe strains, for example an avian influenza, infection resolution may require additional time and infection could be characterized by significant viral loads. In the absence of immunity, a chronic infection characterized by a sustained viral load is observed that is not terminated unless effective treatment is implemented. Hence, the immune response should be necessarily included in an influenza model in order to be capable of reproducing the full spectrum of infection profiles observed in patients.

\footnotetext{
${ }^{1}$ Viral titer is an experimental measure of the concentration of virus in a sample.
} 


\subsection{Immune response induced against influenza infections}

The immune system is responsible for defense against foreign agents such as viruses. Foreign antigens are recognized as harmful agents by the immune system. In order to eliminate foreign pathogens and prevent them from colonizing host cells, the immune system recruits a wide range of cellular and molecular agents. The immune response acts on two time scales; the innate immunity, which is the first to step, is followed by a slower adaptive immune response. A thorough overview of both components of the immune response is provided in [28].

\subsubsection{Innate immunity}

The innate immunity is not antigen-specific and does not require previous acquaintance with the antigen. It consists of cells such as monocytes, phagocytes, macrophages, and dendritic cells. These cells communicate with other immune cells through molecules known as cytokines. Cytokines act as messengers between different immune and host cells involved in the infection. An antigen stimulates cytokine secreting cells to release cytokines. These cytokines are captured by cytokine receptors on their target cells. These target cells in turn respond to cytokines resulting in biological effects, such as an up-regulation or down-regulation of specific genes, or an increase in the number of their receptors for other molecules.

Cytokines encompass a large number of different molecules such as interleukins, tumor necrosis factor- $\alpha$, transforming growth factor $\beta$, and interferons. Interferons are known to induce an antiviral state in cells and down regulate viral production by infected cells. They consist of two main types: interferon type I consist of interferon- $\alpha$ which are produced by macrophages, and interferon- $\beta$ by fibroblasts. Interferon type I acts by inducing an antiviral state in most nucleated cells and activating natural killer cells. Interferon type II mainly consists of interferon- $\gamma$, which is secreted by $\mathrm{T}$ helper cells, T killer cells and natural killer cells. Type II interferon activates macrophages. Both types of interferon increase antigen expression.

The innate immune response is known to play an important role in reducing viral titer early during the infection. Several studies have measured interferon (IFN) concentration during experimental influenza infections. Sample IFN titers, as well as a sample viral titer in the presence and absence of IFN, are shown in Fig. 1.4. Since a lot is known about their properties and behavior, several modelling studies chose interferon as a representative of the entire immune response [2,67]. IFN is chosen to represent innate immunity in this project. 

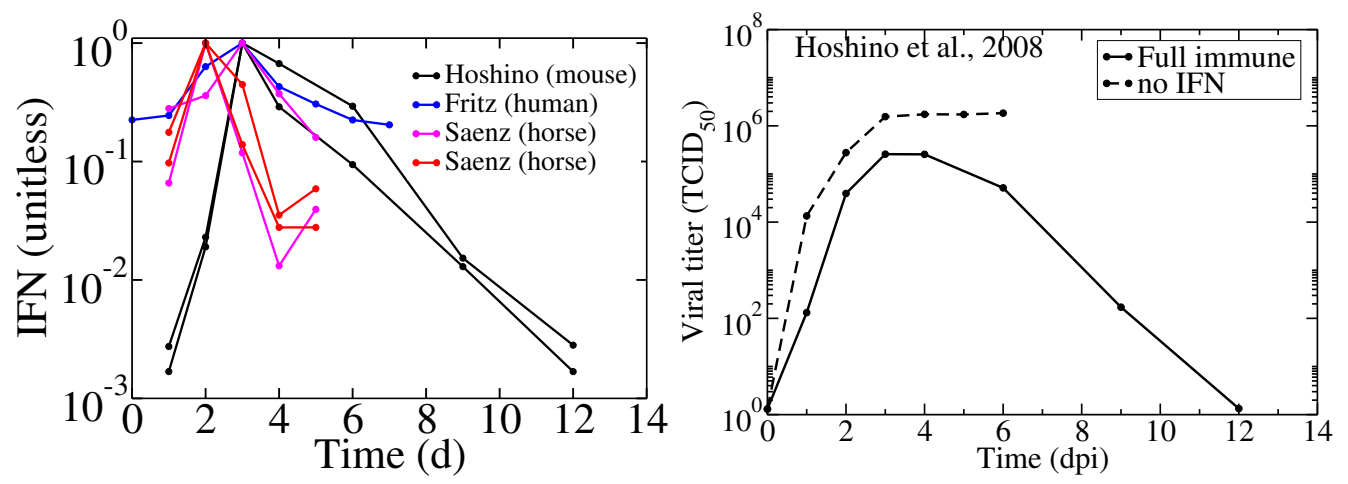

Figure 1.4: Sample interferon time courses in humans and animals and their effect on viral titer in mice. The left hand panel shows interferon (IFN) titers as extracted from published studies by Hoshino et al., 2008 and Iwasaki et al., 1977 whose experiments were conducted in mice [39,41], by Fritz et al., 1999 in humans [26] and by Saenz et al., 2010 in horse [67]. All data peaks are scaled to 1. The right hand panel shows viral titer for immunocompetent mice with IFN (solid lines) and immunocompromised mice in whom IFN was suppressed (dashed lines). This figure is a courtesy of Dr. Hana Dobrovolny.

\subsubsection{Adaptive immunity}

Activated by the presence of an antigen and by the innate immune response, the adaptive immune response steps in to help clear the intruder. This type of immune response is antigen-specific. It has the ability to recognize new antigens, stimulate an effective elimination mechanism, and retain memory of the intruder. Hence, it can elicit a faster and stronger response upon subsequent encounters with an antigen.

The adaptive immune response has two main components; the humoral adaptive response which is mainly mediated by antibodies secreted by plasma cells, and the cellmediated response which is mainly mediated by helper and cytotoxic $\mathrm{T}$ cells and natural killer cells. Helper T cells activate B cells to differentiate into plasma, antibody secreting cells, whereas cytotoxic $\mathrm{T}$ cells induce death in cells presenting foreign antigens. $\mathrm{B}$ cells and $\mathrm{T}$ cells, once activated, proliferate and differentiate into effector cells actively involved in clearing the pathogen. Some of these cells become long-lived memory cells. Thus, a primary encounter with an antigen leads to immunization against this particular antigen.

Antibodies can be cell-bound or free immunoglobulins ( $\mathrm{Ig}$ ). Based on differences in their structure, antibodies can be classified into the isotypes: $\operatorname{IgG}, \operatorname{IgM}, \operatorname{IgA}, \operatorname{IgE}$ and $\operatorname{IgD}$. IgG is the most abundant class of antibodies in serum. IgMs are produced in serum 

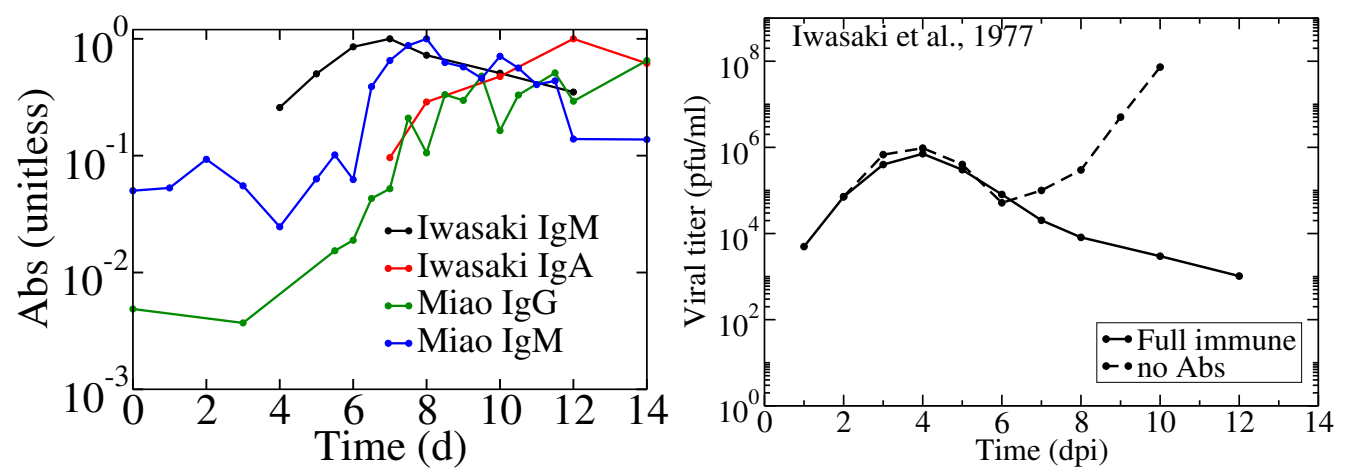

Figure 1.5: Sample antibody time courses in mice and their effect on viral titer in mice. The left hand panel shows antibodies' (Abs) titers as extracted from published studies by Miao et al., 2010, and Iwasaki et al., 1977, whose experiments were conducted in mice $[41,53]$. The peak of antibody measurements are scaled to 1 . The right hand panel shows viral titer for immunocompetent mice with Abs (solid lines) and immunocompromised mice in whom Abs were suppressed (dashed lines). This figure is a courtesy of Dr. Hana Dobrovolny.

before sufficient amount of $\operatorname{IgG}$ is produced. IgA is the main antibody class present in mucosal areas. IgG, IgM and IgA are the main antibody classes found in the lung [42].

Between the humoral- and cell-mediated immunity, the former appears to have the most pronounced impact in limiting an influenza infection. A previous model of influenza infections in mice by Miao et al. showed that IgG antibodies had the most relevant effect in suppressing the influenza infection compared to a very limited effect of for cytotoxic $\mathrm{T}$ cells [53]. Antibody (Ab) measurements are also common when studying influenza infections, sample antibody time courses, as well as a sample viral titer in the presence and absence of Abs, are shown in Fig. 1.5. These antibodies are known to become detectable at around $5 \mathrm{dpi}$, peak at $7 \mathrm{dpi}$ [42], and persist at elevated levels for several weeks after primary contact with antigen [12]. They form immune complexes with virions thus preventing them from binding to, and invading, host cells or they tag antigens so that other immune cells can eliminate them.

\subsection{Motivation}

In constructing a realistic spatial model of influenza infection, several biological processes must be considered. For example, there are two possible viral transport modes: diffusion in the periciliary fluid (PCF) and its upwards advection. The mucus layer is known to drive the entire bulk of the PCF upwards driving along with it virus. Viral diffusion in 
a cell culture was previously studied in a PDE model by Holder et al. [37], but to this date no similar model exists for an in vivo situation. Furthermore, to my knowledge the effect of virus advection due to entrainment by the mucosal escalator has not been previously evaluated. A spatial model for in-host dynamics of influenza infection, which takes virus diffusion and advection into consideration, is evidently needed.

A realistic model should be able to reproduce the kinetics of different categories of influenza infections. Influenza infection takes one of three forms shown in Fig. 1.3: a seasonal infection with a human-derived strain of limited severity that is resolved within one week, a severe infection characterized by a sustained high viral titer load lasting a few weeks that is typically caused by a novel pandemic strain, and a chronic infection that lasts for extended periods of time, up to several months, due to an impaired or nonfunctional immune response $[10,13,23,45,79]$. One particular problem with previously published models is their inability to reproduce the three types of infection encountered by patients as was shown by Dobrovolny et al. [24].

Cellular regeneration following cell death is speculated to be necessary for the establishment of a chronic infection, where immune interference is expected to impede and terminate the infection into a seasonal or a severe form. The presence of preexisting immunity, on the other hand, was found to delay the onset of disease and facilitate recovery $[30,47]$. While a few ordinary differential equation models incorporate both cellular regeneration and some form of immunity, they do not replicate a chronic infection when immune interference is turned off in the model, and a seasonal infection with reasonable parameters when the immune interference is turned back on except for one model by Bocharov et al., consisting of 13 equations and more than 40 parameters, in which antibodies have a very limited effect $[12,24]$. Furthermore, some of the existing models consist of a large number of variables and parameters. A model that can capture all three types of infection without excessive complication and over-parametrization will be a useful tool for characterizing influenza infections.

In order to avoid over-parameterization of models, several models with simplified assumptions for the immune response were developed by many researchers. For example, Saenz et al., 2010, constructed a model with an immune response that consists of interferons only, which were found to limit the peak of viral titer and hence reduce infection severity [67]. Miao et al., 2010, included antibodies in their model without modelling the activation of $\mathrm{B}$ cells, their proliferation and differentiation, and finally antibody release [53]. Instead, Abs measurements over time were used. Similarly, Handel et al. modelled the effect of Abs and used a mathematical function of their concentration fitted to experimental measurements in mice. The effect of antibodies and antibody titer was 
modelled explicitly in the system of ODEs [31].

In this work, we construct a spatiotemporal model of influenza infection in a human host by using partial differential equations (PDEs). By implementing a simplified, onedimensional representation of the respiratory tract (RT), this model will allow us to study in vivo viral transport modes. We incorporate two variants of cellular regeneration into our model as well as simplified innate and adaptive immune responses, via an interferon and antibody response, respectively, in order to better account for the infection kinetics. 


\section{Chapter 2}

\section{Methods}

\subsection{Mathematical model}

The model proposed by Baccam et al. is extended to include spatial effects by explicitly modelling viral transport in the human respiratory tract [2]. The respiratory tract which is modelled with a simplified geometry as a one dimensional tract. A partial differential equation model tracks the system's temporal and spatial evolution, to account for diffusion of virus in the PCF as well as its upward advection due to entrainment by mucus. The basic model is given by:

$$
\begin{aligned}
\text { Target : } & \frac{\partial T(x, t)}{\partial t}=-\beta T(x, t) V(x, t) \\
\text { Eclipse : } & \frac{\partial E(x, t)}{\partial t}=\beta T(x, t) V(d, x)-k E(x, t) \\
\text { Infectious : } & \frac{\partial I(x, t)}{\partial t}=k E(x, t)-\delta I(x, t) \\
\text { Dead : } & D(x, t)=N(x)-T(x, t)-E(x, t)-I(x, t) \\
\text { Virus : } & \frac{\partial V(x, t)}{\partial t}=p I(x, t)-c V(x, t)+D_{P C F} \frac{\partial^{2} V(x, t)}{\partial x^{2}}+v_{a} \frac{\partial V(x, t)}{\partial x} .
\end{aligned}
$$

where $N(x)=T(x, 0)+E(x, 0)+I(x, 0)+D(x, 0)$, since cells can only be in one of these states and it is assumed that the epithelium cannot overgrow.

The boundary conditions at the top, $x=0$, and bottom, $x=x_{\max }$, of the RT, are:

$$
\frac{\partial V(x=0, t)}{\partial x}=0, \quad \text { and } \quad \frac{\partial V\left(x=x_{\max }, t\right)}{\partial x}=0 .
$$


Target cells, $T$, become infected by virus, $V\left(\mathrm{TCID}_{50} / \mathrm{mL}^{1}\right)$, at a rate $\beta\left(\left(\mathrm{TCID}_{50} / \mathrm{mL}\right)^{-1} \cdot \mathrm{d}^{-1}\right)$. Once infected, these cells start replicating viral components although they are not yet producing virus; this is called the eclipse phase, $E$. They then become infectious cells, $I$, at a rate $k\left(\mathrm{~d}^{-1}\right)$. During this phase, infectious cells produce virus, $V$, at a rate $p$ $\left(\mathrm{TCID}_{50} / \mathrm{mL} \cdot \mathrm{d}^{-1}\right)$ and die at a rate $\delta\left(\mathrm{d}^{-1}\right)$. The virus diffuses uniformly across the respiratory tract with a diffusion $D_{P C F}\left(\mathrm{~m}^{2} \cdot \mathrm{d}^{-1}\right)$ and advects upwards towards the top of the respiratory tract (decreasing $x$ ) at a speed $v_{a}\left(\mathrm{~m} \cdot \mathrm{d}^{-1}\right)$, it is cleared at a rate $c$ $\left(\mathrm{d}^{-1}\right)$. In this model, target, eclipse, infectious and dead cells are stationary and evolve with time only. Hence the equations governing them involve derivatives with respect to time only. The virus equation involves spatial derivatives that explicitly govern its transport through the respiratory tract. Through these transport modes virus becomes available to susceptible target cells which can lead to their infection.

\subsection{Parameter estimates}

The baseline infection kinetics parameters are those estimated by Baccam et al [2]. The parameters were obtained by fitting their model to patient data from experimental infections with influenza A/Hong Kong/123/77 (H1N1) and are presented in Table 2.1.

Virus particles, called virions, of radius R diffuse uniformly in the PCF with a diffusion rate $D_{P C F}$ which is determined by the Stokes-Einstein relationship

$$
D_{P C F}=\frac{k_{B} T}{6 \pi R \eta}
$$

where $k_{B}$ is the Boltzmann constant, $k_{B}=1.38 \times 10^{-23} \mathrm{~m}^{2} \cdot \mathrm{kg} \cdot \mathrm{s}^{-2} \cdot \mathrm{K}, T$ is the human body temperature $T=310.5 \mathrm{~K}, \eta=1.43 \times 10^{-3} \mathrm{~kg} \cdot \mathrm{s}^{-1} \cdot \mathrm{m}^{-1}$ which is approximately that of plasma (assumed to be similar to that of the PCF), and the virion's radius, $R$ is approximately $50 \mathrm{~nm}$ [44]. Hence, the biologic diffusion rate for virions in the periciliary fluid is estimated as $D_{P C F} \approx 10^{-12} \mathrm{~m}^{2} \cdot \mathrm{s}^{-1}$ [8]. The rate of diffusion was varied in the absence of advection to study its effect but otherwise was kept fixed at $10^{-12} \mathrm{~m}^{2} \cdot \mathrm{s}^{-1}$ throughout the rest of the simulations.

From the literature, it was found that the speed of the mucosal blanket ranges between $13 \mu \mathrm{m} / \mathrm{s}$ and $213 \mu \mathrm{m} / \mathrm{s}$ as measured by detecting inhaled florescent or radioactive markers $[11,51,82,86]$. An intermediate value of $v_{a}=40 \mu \mathrm{m} / \mathrm{s}$ was chosen for our simulations [51].

\footnotetext{
${ }^{1}$ tissue culture infectious dose: the amount of a pathogenic agent that will produce pathological change in $50 \%$ of cell cultures inoculated.
} 
Table 2.1: Default initial conditions and parameter values of the target cell limited model. All parameters are from Baccam et al. except for the viral production $p$ which is what we used in all of the simulations except for the simple diffusion-only simulations in which production is $p_{\text {Baccam }}=0.046 \mathrm{TCID}_{50} / \mathrm{mL} \cdot \mathrm{d}^{-1}$.

\begin{tabular}{lcc}
\hline \hline symbol & parameter & value \\
\hline \hline$T_{0}$ & number of initially available target cells & $4 \times 10^{8}$ cells \\
$E_{0}, I_{0}$ & number of initially infected cells & 0 \\
$D_{0}$ & number of initially dead cells & 0 \\
$V_{0}$ & initial viral inoculum & $6.6 \times 10^{-2} \mathrm{TCID}_{50} / \mathrm{mL}$ \\
\hline $1 / k$ & length of eclipse phase & $4.6 \mathrm{~h}$ \\
$1 / \delta$ & lifespan of productively infected cells & $4.6 \mathrm{~h}$ \\
$1 / c$ & time required for clearance of virions & $3.2 \times 10^{-5}\left(\mathrm{TCID}_{50} / \mathrm{mL}^{-1} \cdot \mathrm{d}^{-1}\right.$ \\
$\beta$ & infection rate of cells by virus & $0.49 \mathrm{TCID}_{50} / \mathrm{mL}^{-1} \mathrm{~d}^{-1}$ \\
$p$ & virus production rate &
\end{tabular}

\subsection{From zero-dimensional to 1 -d formulation}

The respiratory tract (RT) is represented as a one-dimensional grid with the top of the respiratory tract at $x=0 \mathrm{~cm}$ and the bottom at $x=0.3 \mathrm{~m}$. In this model of the RT, we include the conducting airways only up to the end of the bronchi (first generation) while excluding the nose. The length of the nasopharyngeal tract was estimated by dividing the naso-pharyngeal tract volume by its surface area as estimated by Guilmette et al., 1997, [29] for a human of $170 \mathrm{~cm}$ height, which is the height of the reference man [40] assuming a cylindrical geometry where a directly measured value could not be found; the consecutive lengths of the nose, larynx, trachea, and bronchi were obtained from morphometric measurements $[63,74,81]$. The total length was found to be $\approx 30 \mathrm{~cm}$. When presenting our results, we show the fraction of cells from the entire RT. For virus, we show the amount present in the top $5 \mathrm{~cm}$ of the RT as virus is typically sampled from the top of the RT via nasopharyngeal swabs.

Since influenza infection is typically initiated by respiratory aerosols from infected individuals, we emulate this by setting an initial spatial distribution, $V(x, 0)$, of the amount of virus deposited, $V_{0}$. We choose the initial virus distribution to be a Gaussian function centered at the droplet deposition depth, $x_{d}$ with a size determined by the standard deviation, $\sigma$ :

$$
V(x, 0)=\frac{V_{0}}{\sqrt{2 \pi \sigma^{2}}} \exp ^{-\frac{\left(x-x_{d}\right)^{2}}{2 \sigma^{2}}}
$$


The initial number of target cells, $T_{0}$, as well as virus, are distributed uniformly in computational boxes of length $\Delta x$, and the total length of the RT is $L$ such that

$$
T(x, 0)=\frac{T_{0}}{N_{x}}
$$

where

$$
N_{x}=\frac{\Delta x}{\mathrm{~L}}
$$

for simulation accuracy $N_{x} \geq 1000$.

In order to retain dynamics equivalent to the ODE model in each computational box the parameter $\beta$ needs to be rescaled locally as

$$
\beta \rightarrow \beta \times N_{x}
$$

This rescaling is due to a changed number of target cells and amount of virus in each computational box.

The system behaviour was tested by spatial simulations to verify proper and accurate transport of virus across the respiratory tract.

\subsection{Numerical formulation}

To solve the system of equations shown in Eq. (2.1) we use Euler's method for the ordinary differential equations for cellular populations. First, we transfer the differential equations into a finite difference form, such that $\partial t \rightarrow \Delta t$ and $T(x, t) \rightarrow T_{i}^{n}, T_{i}^{n}$ is the number of target cells present at the $i^{\text {th }}$ position at the $n^{\text {th }}$ time step, for example, $T(x-\Delta x, t+\Delta t) \rightarrow T_{i-1}^{n+1}$. Hence the target cell equation above can be rewritten as

$$
\frac{T_{i}^{n+1}-T_{i}^{n}}{\Delta t}=-\beta T_{i}^{n} V_{i}^{n}
$$

which can be rearranged into

$$
T_{i}^{n+1}=T_{i}^{n}-\Delta t \beta T_{i}^{n} V_{i}^{n}
$$

Similarly, all cell population equations can be rewritten as

$$
\begin{aligned}
T_{i}^{n+1} & =T_{i}^{n}-\Delta t \beta T_{i}^{n} V_{i}^{n} \\
E_{i}^{n+1} & =E_{i}^{n}+\Delta t\left[\beta T_{i}^{n} V_{i}^{n}-k E_{i}^{n}\right] \\
I_{i}^{n+1} & =I_{i}^{n}+\Delta t\left[k E_{i}^{n} V_{i}^{n}-\delta I_{i}^{n}\right] .
\end{aligned}
$$


For the virus equation which depends on both space, $x$, and time, $t$, we use the unconditionally stable Crank-Nicolson method while disregarding the advection. The boundary condition can be written in the finite form at the $n^{t h}$ time step at $i=0$ and $i=i_{x_{\max }}$ location as

$$
\frac{V_{1}^{n}-V_{0}^{n}}{\Delta x}=0, \quad \text { and } \quad \frac{V_{i_{x_{\max }}^{n}+1}-V_{i_{x_{\max }}^{n}}^{n}}{\Delta x}=0
$$

The reasoning outlined below results in the unconditionally stable solution of the diffusion problem by the Crank-Nicolson implicit method. Eq. 2.2 is solved with diffusion only then virus advection is enforced by moving the virus at each site by distance, $\Delta x$, at every time step, $\Delta t$, such that $\Delta t$ is determined by $\Delta t=\Delta x / v_{a}$. This condition is necessary for the stability of the advection equation.

In the case where only diffusion is considered, the boundary condition at both ends of the RT is $\frac{\partial V(x, t)}{\partial x}=0$, or in finite form as: $\frac{V_{i+1}^{n}-V_{i}^{n}}{\Delta x}=0$. In the presence of advection, however, this boundary condition is not important as the solution moves at the great speed of advection, $v_{a}$. At the boundaries, the moving solution progresses undisturbed.

Combining the advection by translation of the solution to the Crank-Nicolson scheme for diffusion yields

$$
\begin{gathered}
\frac{\partial V}{\partial t}=D_{P C F} \frac{\partial^{2} V}{\partial x^{2}} \\
\frac{V_{i}^{n+1}-V_{i}^{n}}{\Delta t}=\frac{D_{P C F}}{2}\left[\frac{V_{i+1}^{n+1}-2 V_{i}^{n+1}+V_{i-1}^{n+1}+V_{i+1}^{n}-2 V_{i}^{n}+V_{i-1}^{n}}{(\Delta x)^{2}}\right] \\
\left.2 V_{i}^{n+1}-2 V_{i}^{n}=\frac{D_{P C F} \Delta t}{(\Delta x)^{2}}\left[\left(V_{i+1}^{n+1}-2 V_{i}^{n+1}+2 V_{i-1}^{n+1}\right)+V_{i+1}^{n}-2 V_{i}^{n}+V_{i-1}^{n}\right)\right] \\
-\alpha V_{i-1}^{n+1}+(2+2 \alpha) V_{i}^{n+1}-\alpha V_{i+1}^{n+1}=\alpha V_{i-1}^{n}+(2-2 \alpha) V_{i}^{n}+\alpha V_{i+1}^{n}
\end{gathered}
$$

where $\alpha=D_{P C F} \Delta t /(\Delta x)^{2}$.

In matrix form the virus equation can be written as

$$
[\mathbf{A}]\left[V^{n+1}\right]=[\mathbf{B}]\left[V^{n}\right],
$$

where the matrices $[\mathbf{A}]$ and $[\mathbf{B}]$ have the following forms, 


$$
[\mathbf{A}]=\left[\begin{array}{ccccc}
2+\alpha & -\alpha & 0 & \cdots & 0 \\
-\alpha & 2+2 \alpha & -\alpha & \ddots & \vdots \\
0 & -\alpha & 2+2 \alpha & \ddots & 0 \\
\vdots & \ddots & \ddots & \ddots & -\alpha \\
0 & \cdots & 0 & -\alpha & 2+\alpha
\end{array}\right] \quad[\mathbf{B}]=\left[\begin{array}{ccccc}
2-\alpha & \alpha & 0 & \ldots & 0 \\
\alpha & 2-2 \alpha & \alpha & \ddots & \vdots \\
0 & \alpha & 2-2 \alpha & \ddots & 0 \\
\vdots & \ddots & \ddots & \ddots & \alpha \\
0 & \ldots & 0 & \alpha & 2-\alpha
\end{array}\right]
$$

The equation is solved as:

$$
\left[V^{n+1}\right]=[\mathbf{M}] \times\left[V^{n}\right]
$$

with

$$
[\mathbf{M}]=\left[\mathbf{A}^{-1}\right] \times[\mathbf{B}]
$$

Now advection is enforced by moving the virus at each site by a distance $\Delta x$ at every time step, $\Delta t$ :

$$
V_{i}^{n+1}=V_{i+1}^{n}
$$

In addition to diffusion and advection, the virus, $V(x, t)$, is also subject to infection kinetics which can be treated separately after the virus diffuses and drifts. Infection kinetics are accounted for by integrating the virus equation with respect to time by separation of variables

$$
\begin{aligned}
& \frac{\partial V(x, t)}{\partial t}=p I(x, t)-c V(x, t) \\
& \frac{\partial V(x, t)}{p I(x, t)-c V(x, t)}=\mathrm{d} t \\
& \int_{V_{t}}^{V_{t+\mathrm{d} t}} \frac{\partial V(x, t)}{p I(x, t)-c V(x, t)}=\int_{t}^{t+\mathrm{d} t} \mathrm{~d} t \\
& \ln [p I(x, t)-c V(x, t+\mathrm{d} t)]-\ln [p I(x, t)-c V(x, t)]=-c \mathrm{~d} t \\
& \ln \left[\frac{p I(x, t)-c V(x, t+\mathrm{d} t)}{p I(x, t)-c V(x, t)}\right]=e^{-c \mathrm{~d} t} \\
& V(x, t+\mathrm{d} t)=\frac{p I(x, t)}{c}\left(1-e^{-c \mathrm{~d} t}\right)+V(x, t) e^{-c \mathrm{~d} t} .
\end{aligned}
$$

The final form of the virus equation can be written finitely

$$
V_{i}^{n+1}=\frac{p I_{i}^{n}}{c}\left(1-e^{-c \mathrm{~d} t}\right)+V_{i}^{n} e^{-c \mathrm{~d} t} .
$$




\section{Chapter 3}

\section{Viral transport modes}

\subsection{Virus diffusion in the periciliary fluid}

The epithelial cells of the human RT are covered in a thin layer of liquid called the PCF. Infection of cells by the influenza virus, and the subsequent release of influenza virions, occurs almost exclusively at the apical surface of the epithelium [14,54] and therefore the PCF mediates the spread of an infection throughout the RT. When directional motion of the $\mathrm{PCF}$ is neglected, virions can be assumed to follow Brownian motion and the virus concentration in the $\mathrm{PCF}$ will be governed by diffusion with coefficient given by the Stokes-Einstein equation $D_{P C F} \approx 10^{-12} \mathrm{~m}^{2} \cdot \mathrm{s}^{-1}$.

Typical influenza models are mostly based on ordinary differential equations. In such models, the system evolves in time and assumes a homogeneity in the distribution of cell populations and virus which means that any amount of virus becomes immediately available to all target cells. Since we explicitly model the transport of virus via diffusion $D_{P C F}$, which is an essentially different situation from the infinite diffusion assumed implicitly in ODE models, we first explored the effect of changing the rate of diffusion $D_{P C F}$ on infection kinetics. Fig. 3.1 shows a study of the effect of the viral diffusion coefficient ranging from $10^{-8}-10^{-12} \mathrm{~m}^{2} \cdot \mathrm{s}^{-1}$ in the absence of advection (i.e. $v_{a}=0$ ) while depositing viral inoculum at depths of $x_{d}=0.01 \mathrm{~m}$ and $x_{d}=0.15 \mathrm{~m}$. Spatial simulations show that virus becomes available to target cells gradually as it diffuses away from the site of deposition such that neighboring cells become infected first, and further cells follow (results not shown). When compared to the ODE model, target cell infection takes place at a slower pace as the rate of diffusion, $D_{P C F}$, is decreased.

Due to asymmetry in the site of deposition with respect to the RT when $x_{d}=0.01 \mathrm{~m}$, virus diffuses out of the top of the RT $(x=0)$ before it reaches the bottom of the RT 

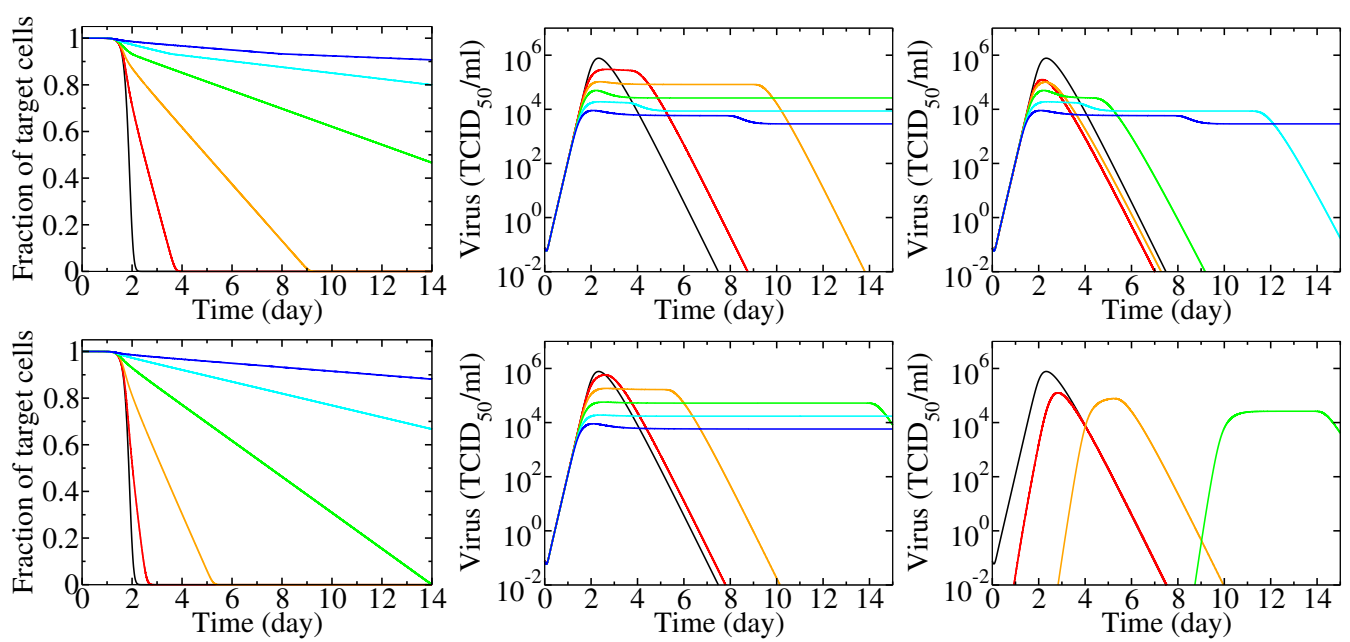

Figure 3.1: The effect of varying the rate of viral diffusion. Consumption of target cells (leftmost column) and viral titer, sampled from the entire RT (middle column) and from the top $0.05 \mathrm{~m}$ (rightmost column), for different diffusion rates is shown. Virus is deposited at $x_{d}=0.01 \mathrm{~m}$ and $x_{d}=0.15 \mathrm{~m}$ in the top and bottom rows respectively. The colours red, orange, green, cyan, and blue correspond to diffusion rates decreasing from $10^{-8} \mathrm{~m}^{2} \cdot \mathrm{s}^{-1}$ to $10^{-12} \mathrm{~m}^{2} \cdot \mathrm{s}^{-1}$ in steps of one order of magnitude respectively. The blue line corresponds to the biologic diffusion of $10^{-12} \mathrm{~m}^{2} \cdot \mathrm{s}^{-1}$. The black line shows the consumption of target cells and viral titer profile under infinite diffusion, as is assumed by ordinary differential equations using parameters from Baccam et al., 2006.

$(x=0.3 \mathrm{~m})$. This can be seen as a slight drop in the viral titer followed by a decay once virus has crossed the lower end of the RT as well. When target cells are completely depleted, viral titer decay is observed, and occurs sooner as the diffusion rate increases. When virus is deposited at $x_{d}=0.15 \mathrm{~m}$, it reaches opposite ends of the RT at the same time and one phase of decay is observed.

As we sample virus from the top $0.05 \mathrm{~m}$, when virus is deposited deeper, it will need more time to travel to the top of the RT and peak there. This travel is further delayed by a slow rate of diffusion $D_{P C F}$ as can be seen in Fig. 3.1. There is no delay when virus is deposited at $0.01 \mathrm{~m}$, and the time and rate of decay depends on the rate of diffusion $D_{P C F}$. This does not mean, however, that the infection cannot proceed deeper in the RT when not accounting for the effect of advection which will be shown in the next section. 


\subsection{Virus entrainment in the mucosal elevator and a thresh- old for infection}

Entrainment of influenza virus particles in the rapidly-moving PCF has the potential to dramatically alter the kinetics of an infection (for example, from that of a stationary cell culture), both in the initiation of an infection and its progression. We consider infection initiated by virus deposition at $0.15 \mathrm{~m}$, in the presence of both isotropic diffusion at $10^{-12} \mathrm{~m}^{2} \cdot \mathrm{s}^{-1}$ and upward advection at $40 \mu \mathrm{m} \cdot \mathrm{s}^{-1}$ (Fig. 3.2). Using the same parameters used to successfully fit an ODE model to patient data, a sustained infection did not arise and nearly the entire target cell population was protected. To determine the strength of this protective effect, we therefore increased the viral production rate, $p$.

The profile of target and infectious cells and virus for different production rates is shown in Fig. 3.2. Advection dominates the dynamics (the timescale on which diffusion acts is much longer than the time to sweep virus out of the RT) and it indeed demonstrates that mucus is an effective physiological mechanism to suppress infection. Viral titers of an influenza infection typically peak between $2-3$ dpi $[2,12,62,84]$. We found that an increase of $\approx 11$ fold in the production rate is sufficient for an infection to embark and progress despite the overwhelming drift of virus while peaking at day 2 post infection. We will use this new value of $p(p \approx 11$ fold greater than the value estimated by Baccam et al., 2006) for the remainder of our investigations as this value reproduces qualitatively the profile for an influenza infection in our model.

Once production is large enough to cause infection, the eventual damage to the RT is limited to the regions through which virus was entrained. Since we deposited virus at $x_{d}=0.15 \mathrm{~m}$, mainly the top $0.15 \mathrm{~m}$ of the RT gets involved in the infection. The infection starts at the top of the RT as the cells located there are exposed to all the virus produced by infection of cells at sites lower in the RT as shown in Fig. 3.3. The infection proceeds downwards very slowly and finally localizes at a depth $\approx 0.11 \mathrm{~m}$ at day 7 post infection and does not proceed any further. It finally dies off at $\sim 12 \mathrm{dpi}$.

Although infection does take off, it is supported by a very limited fraction of infectious cells and the sustained viral loads observed are due to the high production of virus by an extremely small fraction of infectious cells. Chronic infections observed in immunocompromised patients with a limited or impaired immune response are characterized by long lasting, sustained viral titers $[13,45,61,79]$. The viral loads shown in Fig. 3.2 decay due to target cell limitation, and thus do not describe a true chronic infection. 

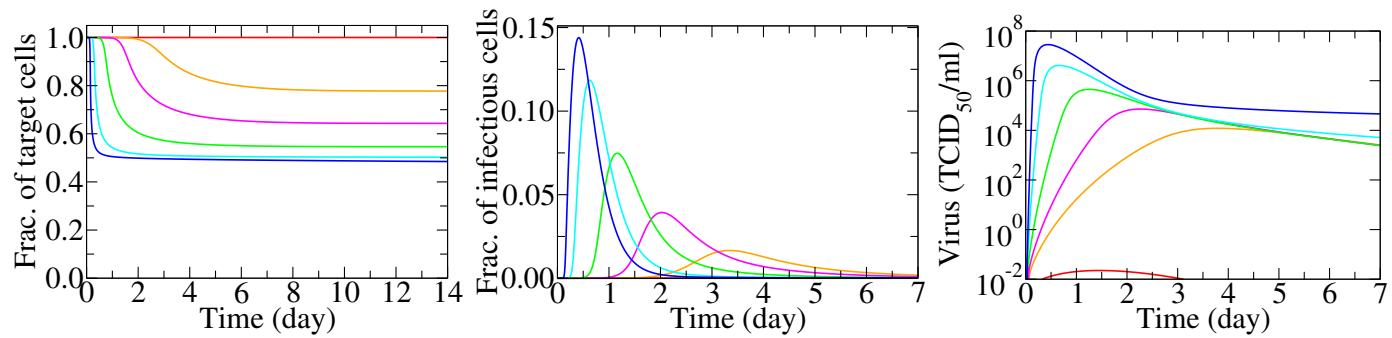

Figure 3.2: The effect of changing production on infection kinetics in the presence of both advection and diffusion. Here production is either $p_{\text {Baccam }}$

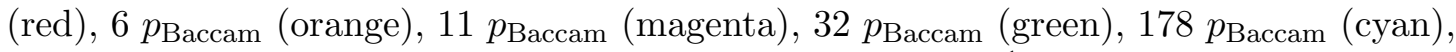
$1000 p_{\text {Baccam }}$ (blue) where $p_{\text {Baccam }}=0.046 \mathrm{TCID} 50 / \mathrm{mL} \cdot \mathrm{d}^{-1}$ chosen because it fits the ODE model to experimental infections.
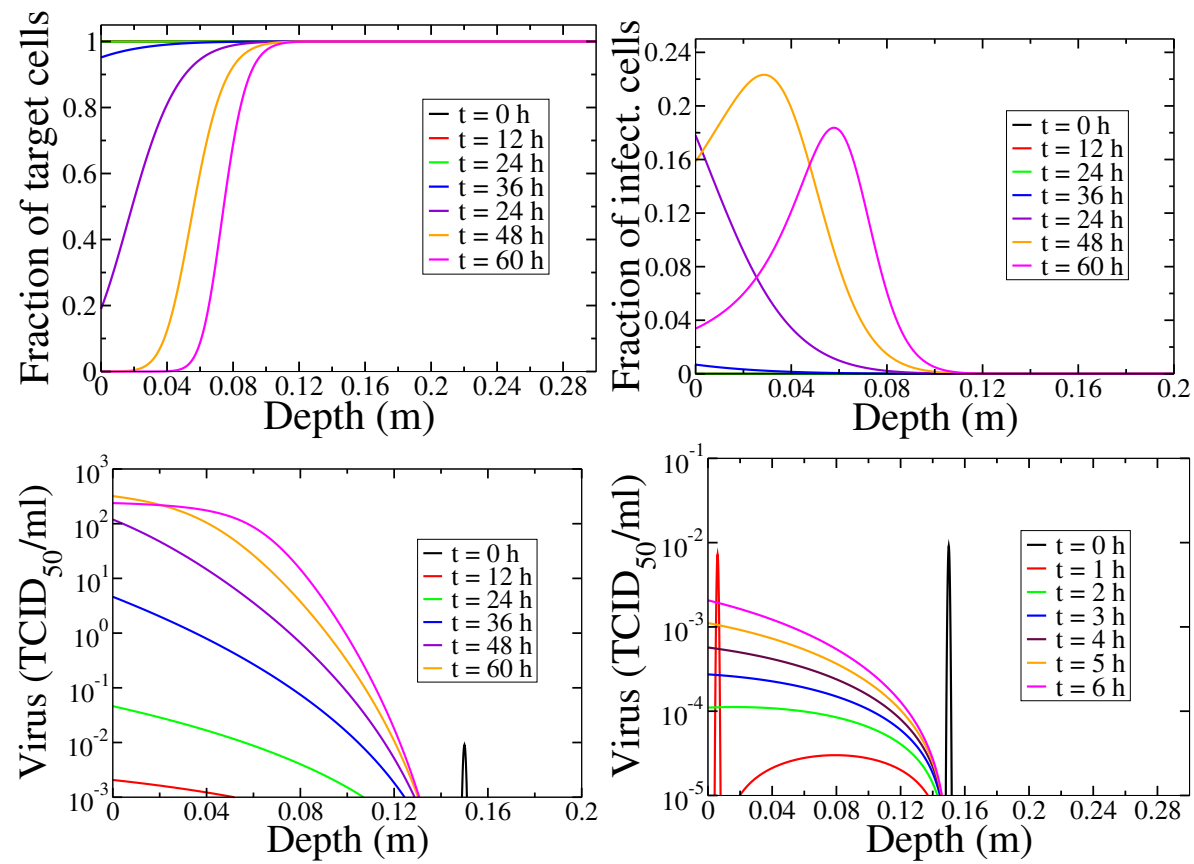

Figure 3.3: Early infection spatial profile. The target and infectious cells profile in the top row shows that infection commences at the top of the RT. The viral titer profile shows that the virus impulse reaches the top of the RT within one hour post infection. Viral growth then is observed at the top of the RT which was exposed to the traversing virus and the virus produced by the very small fractions of cells it infected along its way. 


\section{Chapter 4}

\section{Respiratory tract epithelium regeneration and chronic infections}

As target cell limitation was shown to be a main cause of infection termination, when trying to emulate a chronic infection, cellular regeneration needs to be included in the model. Basal cells are the main progenitors of tracheal and bronchial epithelium in the human RT but they are not targeted by influenza virus $[77,85]$. This suggests that cellular regeneration should not depend on the target cell population. However, these basal cells proliferate and differentiate into infectible cells until the epithelium is restored into its normal state $[17,27,80]$. The fact that susceptible cells arise from the basal cells which are responsible for epithelium replenishment implies that cellular replenishment may be actually dependent on the target cell population. In order to account for cellular regeneration, two variants of repopulation dynamics were explored: a density-independent, and a density-dependent cellular regeneration.

\subsection{Density-independent regeneration}

The first variant is density-independent target cell regeneration model and assumes that cellular regeneration takes place at a rate, $r_{D}$, and is proportional to the damage in the RT (i.e. dead cells),

$$
\frac{\partial T(x, t)}{\partial t}=-\beta T(x, t) V(x, t)+r_{D} D\left(x, t-\tau_{D}\right),
$$


where we allow for a proliferation delay $\tau_{D}$.

This type of regeneration was also implemented by others without a delay $\left(\tau_{D}=0\right)$ $[12,31,47,53]$. This model represents a reservoir of uninfectible and pluripotent cells that are responsible for repairing epithelial damage due to the infection, meaning that there is no damage beyond repair by the reservoir cells. The delay $\tau_{D}$ is biologically justified as a lapse of time before the proper pathways lead to the start of the regeneration process. This is estimated to take between $0-1 \mathrm{~d}[80]$.

Using Euler's method to solve this equation, we have

$$
\begin{gathered}
\frac{T(x, t+\Delta t)-T(x, t)}{\Delta t}=-\beta T(x, t) V(x, t)+r_{D} D\left(x, t-\tau_{D}\right) \\
T(x, t+\Delta t)=T(x, t)+\Delta t \times\left[-\beta T(x, t) V(x, t)+r_{D} D\left(x, t-\tau_{D}\right)\right] .
\end{gathered}
$$

Following the notation introduced in Section 2.4, the above equation can be written as

$$
T_{i}^{n+1}=T_{i}^{n}+\Delta t \times\left[-\beta T_{i}^{n} V_{i}^{n}+r_{D} D_{i}^{n-m}\right],
$$

where $m=\operatorname{round}\left(\frac{\tau_{D}}{\Delta t}\right)$, is the number of time steps corresponding to $\tau_{D}$ or the closest integer to it.

The delay, $\tau_{D}$, requires that dead cells from previous time steps are stored. Since the time step, $\Delta t=\Delta x / v_{a}$, is of the order $10^{-4} \mathrm{~d}$, continuous storage of the dead cells vector for each time step leads to a growing matrix (time $\times$ space) which can exhaust the memory allocated by Octave when long simulations are run. To solve this issue, only the last $m$ time steps in the dead cells matrix are stored.

At the beginning of the simulation, the delay, $\tau_{D}$, is determined, which sets the variable $m$. The built-in Octave function "sparse" is used to minimize the memory requirement in creating this two-dimensional matrix. The algorithm employed in reducing the memory requirement of the program is illustrated in Fig. 4.1. In this model, it is ensured that the epithelium does not overgrow. This is achieved by choosing the minimum of $D_{i}^{n}$ and $\Delta t \cdot r_{D} \cdot D_{i}^{n-m}$.

The following range of regeneration rates is explored: $r_{D}=0.5 \mathrm{~d}^{-1}, 1 \mathrm{~d}^{-1}, 10 \mathrm{~d}^{-1}$ and $100 \mathrm{~d}^{-1}$; and of differentiation delay $\tau_{D}=0 \mathrm{~d}, 1 \mathrm{~d}$ and $3 \mathrm{~d}$ in Fig. 4.2. The regeneration rate $r_{D}$ affects the level of chronic viral titer, the greater the $r_{D}$ the higher the chronic viral titer that changes by one order of magnitude within the shown range. The delay, $\tau_{D}$, determines how smooth the viral kinetics are. When regeneration begins immediately upon any amount of cell death (i.e. when $\tau_{D}=0$ ) infection kinetics are smooth. However, when the delay is set to $1 \mathrm{~d}$ or $3 \mathrm{~d}$, pronounced loss and replenishment is observed in 


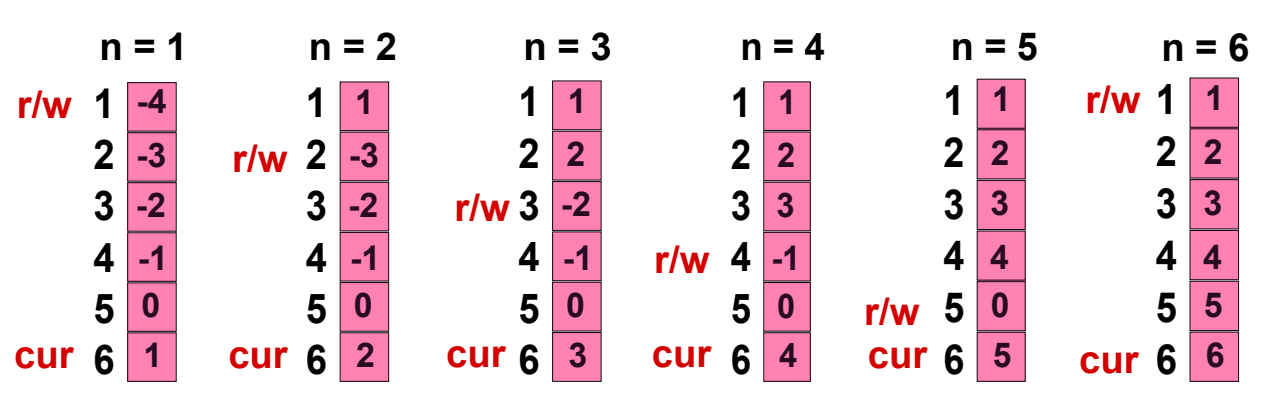

Figure 4.1: The algorithm utilized in reducing the size of the stored dead cells matrix. An example case where $m=5$ is considered for a single site of size $\Delta x$. The length of the time steps vector for a single site in the dead cells vector should be $m+1=6$ so that the current time, "cur", step is stored in the last cell of the array. The element in $n-m$ is read, "r", then overwritten with the current value, "w", in order to be accessed later on as the loop over time steps continues to iterate. The variables " $\mathrm{r}$ " and "w" are set as the integral part of the remainder of the division of $n$ by $m$. This algorithm reduces the memory requirement for a single site from $n$ cells instead of $m+1$ cells.

the target and infectious cells populations translated as sharp growth and decay in the viral titer. This can be explained by the fact that the longer delay between cell death and replenishment results in more dead cells being accumulated and hence triggering a stronger regeneration response to damage. During the time when death of the infectious cells occurs without replenishment viral titer begins to decay as the infectious cells die off gradually without being replaced. When regeneration takes effect, fresh infectible cells are generated that, once infected, will produce virus in a sustained manner. The main difference between the no-delay and delayed cellular regeneration is the temporary uncompensated loss of infectious cells leading to a dip in the otherwise high and sustained viral titer. This behavior is further pronounced when the regeneration rate is high (e.g. $\left.10-100 \mathrm{~d}^{-1}\right)$. Experimentally, the uncertainty in viral titer measurements can be up to 2 orders of magnitude [26], therefore, it would be difficult to validate the observed nonsmooth behaviour given that in humans, virus is rarely sampled more frequently than daily.

When regeneration of dead cells is instantaneous (i.e. $\tau_{D}=0$ ), it is found that a regeneration rate of $1 \mathrm{~d}^{-1}$ is sufficient to establish a chronic infection for an infection that peaks at day 2 . The chronic infection is characterized by a sustained production of virus by $\approx 4 \%$ of cells of the RT as shown in Fig. 4.2. Upon close inspection, a very slow recovery of target cells (or loss in the dead cells) is noticeable, so we do not produce a truly steady-state chronic infection. 

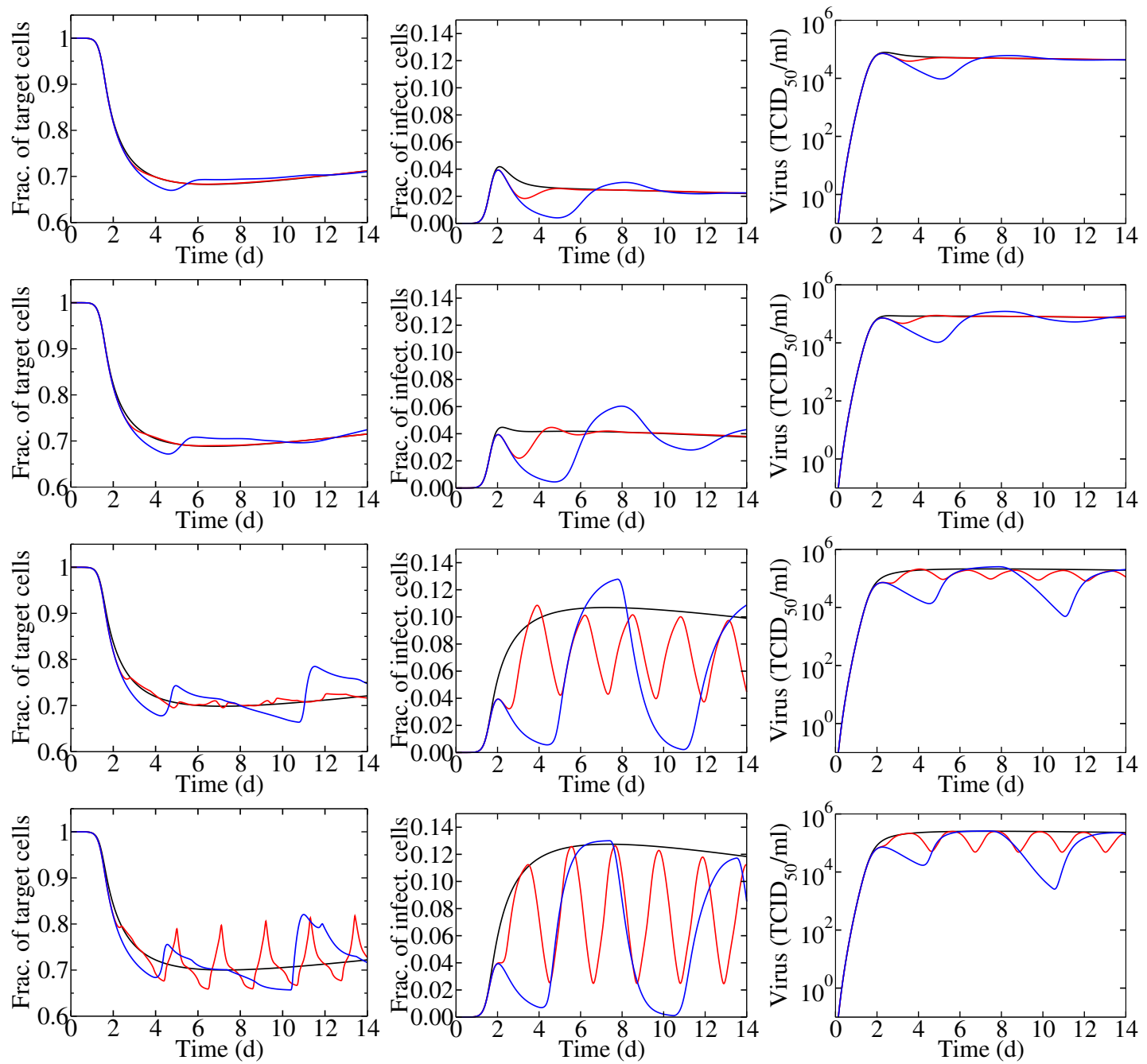

Figure 4.2: Exploring infection dynamics in the density-independent model. The regeneration rate varies from top to bottom as $0.5 \mathrm{~d}^{-1}, 1 \mathrm{~d}^{-1}, 10 \mathrm{~d}^{-1}$ and $100 \mathrm{~d}^{-1}$. The left hand column shows fraction of target cells, the middle column shows fraction of infectious cells and the right hand column shows viral titer. colour scheme as follows: black for $\tau_{D}=0 \mathrm{~d}$, red for $\tau_{D}=1 \mathrm{~d}$ and blue for $\tau_{D}=3 \mathrm{~d}$. 


\subsection{Density-dependent regeneration}

The second variant is density-dependent target cell regeneration model and assumes that cellular regeneration is proportional to damage as well as to available target cells that are capable of proliferation and differentiation, which takes place at a rate, $r_{D T}$,

$$
\frac{\partial T(x, t)}{\partial t}=-\beta T(x, t) V(x, t)+r_{D T} \frac{T(x, t)}{T(x, 0)} D\left(x, t-\tau_{D}\right),
$$

where $\tau_{D}$ is the proliferation delay.

This is equivalent to the standard logistic model of population growth modified by the proliferation delay, $\tau_{D}$. The second variant of the regeneration model assumes that the infectible cell population is also responsible for the replenishment of lung epithelium. This model was used by Hancioglu et al., 2007, [30] without the delay. It was also used to model hepatocyte (liver cells) regeneration in models of hepatitis $\mathrm{C}$ virus infections (HCV) by others $[19,64,71]$.

The density-dependent regeneration equation can be written in Euler's formulation as

$$
\begin{array}{r}
\frac{T(x, t+\Delta t)-T(x, t)}{\Delta t}=-\beta T(x, t) V(x, t)+r_{D T} \frac{T(x, t)}{T(x, 0)} D\left(x, t-\tau_{D}\right) \\
T(x, t+\Delta t)=T(x, t)+\Delta t \times\left[-\beta T(x, t) V(x, t)+r_{D T} \frac{T(x, t)}{T(x, 0)} D\left(x, t-\tau_{D}\right)\right]
\end{array}
$$

Following the notation introduced in Section 2.4, the above equation can be written as

$$
T_{i}^{n+1}=T_{i}^{n}+\Delta t \times\left[-\beta T_{i}^{n} V_{i}^{n}+r_{D T} \frac{T_{i}^{n}}{T_{i}^{0}} D_{i}^{n-m}\right],
$$

where $m=\operatorname{round}\left(\frac{\tau_{D}}{\Delta t}\right)$, is the number of time steps corresponding to $\tau_{D}$ or the closest integer to it. This model is solved using the same algorithm described in section 4.1, also with the constraint on regenerating no more cells than there are dead cells in the current time step.

The effect of varying the regeneration rate, $r_{D T}$, and differentiation delay, $\tau_{D}$, is explored in Fig. 4.3. A similar effect of regeneration rate and delay to those observed in the density-independent target cell regeneration variant can be seen in this model as well. In this model, however, a larger regeneration rate is required for the establishment of a chronic infection. Chronic viral titer changes by two orders of magnitude within the shown range of regeneration rates. This is due to the fact that cellular replenishment in this variant is proportional to target and dead cell populations. 

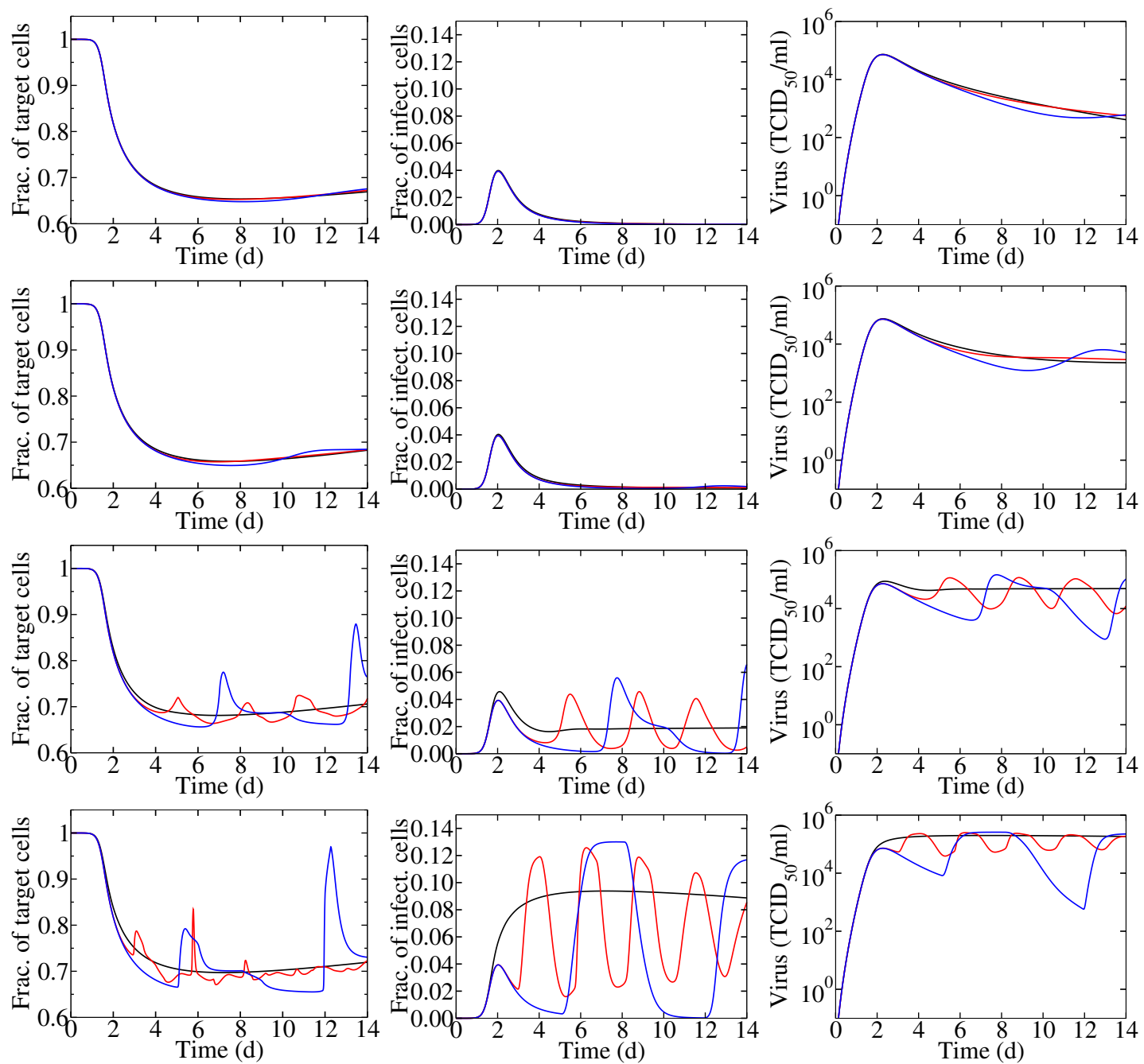

Figure 4.3: Exploring infection dynamics in the density-dependent target cell regeneration model. The regeneration rate varies from top to bottom as $0.5 \mathrm{~d}^{-1}$, $1 \mathrm{~d}^{-1}, 10 \mathrm{~d}^{-1}$ and $100 \mathrm{~d}^{-1}$. The left hand column shows fraction of target cells, the middle column shows fraction of infectious cells and the right hand column shows viral titer. colour scheme as follows: black for $\tau_{D}=0 \mathrm{~d}$, red for $\tau_{D}=1 \mathrm{~d}$ and blue for $\tau_{D}=3 \mathrm{~d}$. 
For this model we find that a regeneration rate $r_{D T}=10 \mathrm{~d}^{-1}$ is sufficient to maintain a chronic infection in the case of immediate regeneration of dead cells as shown in Fig. 4.3 for an infection peaking at $2 \mathrm{dpi}$. The elevated, sustained, viral titer is due to a sustained fraction of infectious cells maintained at $\approx 2 \%$.

The regeneration of target cells depends on the abundance of target cells as they are assumed to constitute the progenitor cell population. Hence, if the damage caused by the infection before regeneration becomes involved is too large, no efficient replenishment occurs. This may occur when the regeneration process does not commence soon enough. Upon introducing a delay of $1 \mathrm{~d}$, as reported in the literature, non-uniform dynamics are observed as in Fig. 4.3. Regeneration is triggered by damage but necessitates that a sufficient fraction of the target cell population, capable of cell division, has survived. Since neither the target cell density nor the dead cell density remain constant throughout the infection course, the regeneration process exhibits alternating intervals of strong activity and idleness.

For the remainder of the simulations in this project, regeneration rate of $1 \mathrm{~d}^{-1}$ and delay of $0 \mathrm{~d}$ are used in the density-independent regeneration model and regeneration rate of $10 \mathrm{~d}^{-1}$ and delay of $1 \mathrm{~d}$ are used in the density-dependent regeneration model. It is noteworthy to point out that both models have similar predictions with a difference in the regeneration rate required to establish a chronic infection. The higher regeneration rate in the density-dependent model is compensated by the fraction of target cells. 


\section{Chapter 5}

\section{The effect of inoculum deposition on infection kinetics}

Influenza infections are mainly initiated by respiratory droplets that land at some depth in the RT. Typically exhaled droplets from individuals infected with influenza virus are less than $1 \mu \mathrm{m}$ in diameter [25]. Upon landing in the RT of another individual, these droplets may further shrink in diameter due to evaporation. Depending on their size, the likelihood and the favorable location of landing in the RT is determined. Particles of less than $1 \mu \mathrm{m}$ in diameter have an almost equal probability of being deposited in the conducting and pulmonary regions, and lesser probability of landing in the pulmonary region [58]. The likelihood of deposition increases with decreasing particle size. The exact size, and consequently the depth, of the coughed particle when it lands in the RT is not determined. Therefore, in this section, the depth of deposition effect on the infection kinetics was explored.

We explored the effect of changing the depth of deposition of viral inoculum in the $\mathrm{RT}$ on the infection kinetics while incorporating cellular regeneration. It can be seen in Fig. 5.1 that the deeper the virus is deposited, the larger the fraction of target cells consumed (up to $80 \%$ of the RT), and infectious cells involved in the infection (up to $13 \%$ at peak). This, in turn, leads to higher viral titers. The fraction of target cells consumed does not reach the fraction of RT depth above the initial depth of deposition of the coughed droplet. This is due to the sweeping effect of mucosal advection. When virus is deposited at $x_{d}=0.01 \mathrm{~m}$ infection is swept out of the RT before it has any chance to diffuse or infect susceptible cells, given our choice of base parameters (Table 2.1).

Comparing the dynamics of different deposition depths, it can be seen that chronic 


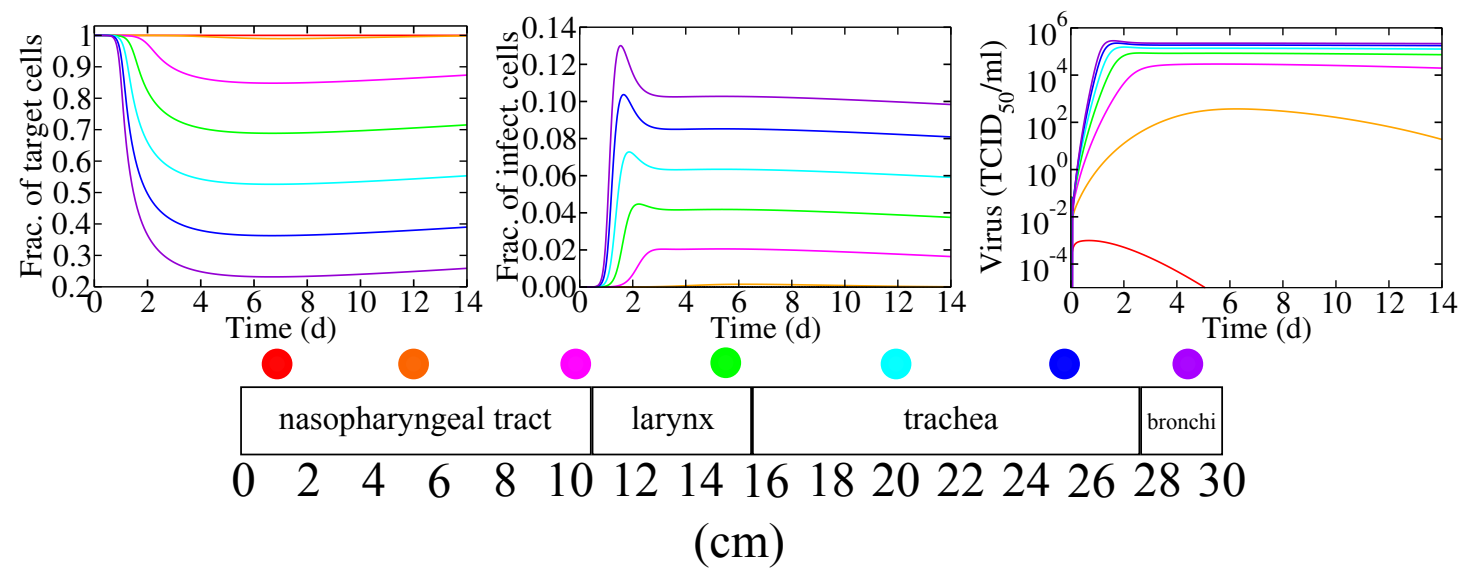

Figure 5.1: The effect of changing the depth of deposition. The depth of deposition varies as $1 \mathrm{~cm}, 5 \mathrm{~cm}, 10 \mathrm{~cm}, 15 \mathrm{~cm}, 20 \mathrm{~cm}, 25 \mathrm{~cm}$, and $29 \mathrm{~cm}$ as shown in colors: red, orange, magenta, green, cyan, blue and violet respectively. The results are shown in the density-independent model with regeneration rate $r_{D}=1 \mathrm{~d}^{-1}$ and no delay, the viral production rate $p \approx 11 p_{\text {Baccam }}$. Note that, in all other Figures, virus is deposited at a depth of $15 \mathrm{~cm}$ corresponding to the green line in this Figure.

infection is achieved for $x_{d} \geq 0.1 \mathrm{~m}$ and peaks earlier as $x_{d}$ increases. These results suggest that there is a minimum depth of viral deposition that must be exceeded for infection to embark in the RT and develop into a chronic infection.

While virus is deposited at some depth $x_{d}$ in the RT, infection embarks at the top of the RT first as indicated by spatial simulations. The initial pulse of virus traversing the RT leads to primary infections along its path. The virus produced by these very limited infections is swept upwards, and the very top of the RT is exposed to all the virus produced since it is located downstream of those primary infections. 


\section{Chapter 6}

\section{Innate and adaptive immune responses and the resolution of infection}

Hitherto, infections in our model are either resolved due to target cell limitation, or due to the sweeping effect of advection. The infection can also develop into a chronic form by virtue of cellular regeneration. Although target cell limitation is speculated to play an important role in resolving influenza infections, very likely it is not the only cause for infection to be terminated. If this was the case, infections with the 2009 pandemic H1N1 strain should not result in the severe infections that were observed. Hence, the immune response is speculated to play an important role in resolving and terminating the infection.

As explained in Chapter 1, we decided to limit the immune response components incorporated in this model and focus on one representative of innate immunity and another for adaptive immunity. We introduce a simplified immune response described by:

- innate immune response: consisting of interferons (IFN); and

- adaptive immune response: consisting of antibodies $(\mathrm{Ab})$,

and determine whether they can model infection resolution. 

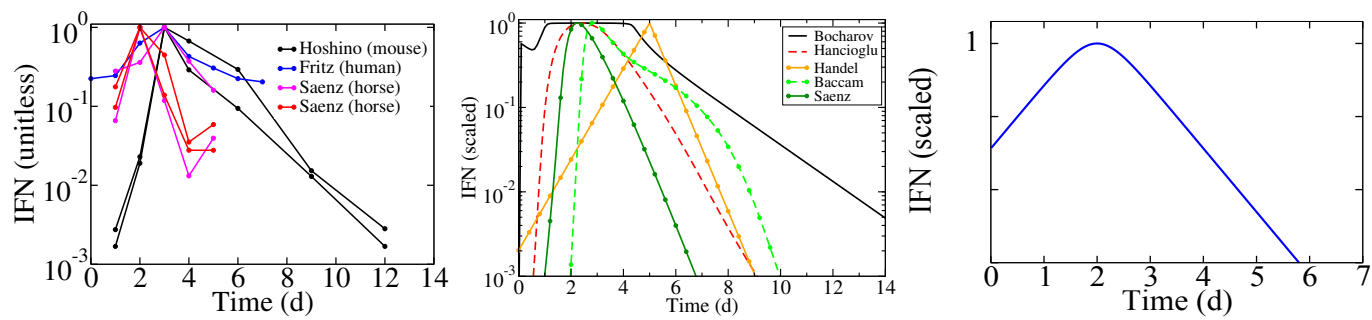

Figure 6.1: The time courses of IFN. The left panel shows experimental titers of IFN in humans and some animals. The center panel shows influenza modelling predictions of IFN time course during the infection. The right panel shows the IFN time course as simulated in this project. The modelled IFN time course here peaks at 2 dpi.

\subsection{Interferon}

Interferons are an important class of cytokines and a lot is known about their action and properties, and hence they are chosen in this project to represent innate immunity. In general, they are known to become elevated early during the infection $[26,33,43,68]$. They appear and become active no later than $24 \mathrm{~h}$ post infection, and their concentration peaks by $1 \mathrm{~d}$ post the viral titer peak $[26,33,66]$. Experimental data from humans, horses, and mice show that they disappear by day 3 to 10 post infection $[26,39,41,67]$.

Since most experimental data suggests a monotonic rise and fall of IFN $[26,31,39$, $41,67]$, we model the amount of IFN with a semi-logarithmic triangular function:

$$
F(t)=\frac{2}{e^{-\lambda_{g}\left(t-t_{p}\right)}+e^{\lambda_{d}\left(t-t_{p}\right)}},
$$

where $\lambda_{g}$ and $\lambda_{d}$ are the growth and decay rates of IFN respectively $\left(\mathrm{d}^{-1}\right)$, the peak amount of IFN is 1 at the time of peak, $t_{p}(\mathrm{~d})$. The IFN time course is shown in Fig. 6.1, where it is also compared to experimental measurements and simulations predictions. Experimental error in these measurements can be up to 2-fold in some experiments [26]. In our simulations we set $\lambda_{g}$ and $\lambda_{d}$ to be $2 \mathrm{~d}^{-1}$ as the growth and decay rates of IFN titers are not significantly different for most data sets as shown in Fig. 6.1.

Although IFN is known to have many effects [72], we model the effect of IFN as reducing the rate of viral production, $p$, homogeneously (independent of $x$ ) $[2,31]$ :

$$
p \rightarrow \frac{p}{1+\frac{F}{\mathrm{IC}_{50}}},
$$

where $\mathrm{IC}_{50}$ is the amount of $\mathrm{IFN}$ required to reduce the viral production rate to one 

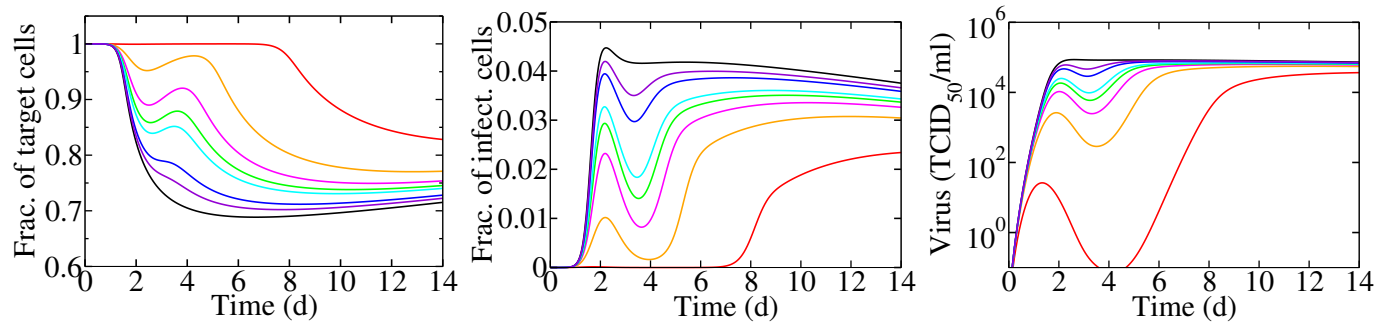

(a)
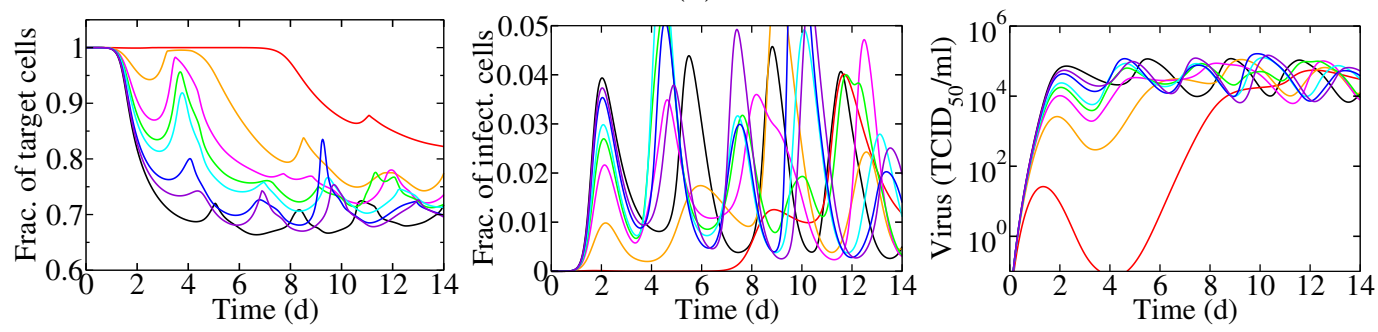

(b)

Figure 6.2: The effect of interferon on infection kinetics. Various values for the effectiveness of the IFN response are considered by varying $\mathrm{IC}_{50}$ in Eq. 6.2 as 1, 5, 10, 15, 20, 50, 100-fold the IFN peak (scaled here to equal 1), corresponding to red, orange, magenta, green, cyan, blue and violet respectively and black corresponds to no IFN. Note that the $\mathrm{IC}_{50}$ is inversely proportional to IFN efficacy with $\mathrm{IC}_{50}=100$ being the least efficacious, and $\mathrm{IC}_{50}=1$ being the most efficacious. The IFN peaks at day 3 post infection with growth and decay rates of $2 \mathrm{~d}^{-1}$. Kinetics are in the absence of any $\mathrm{Ab}$ activity, they are explored in: (a) the density-independent model with $r_{D}=1 \mathrm{~d}^{-1}$ and $\tau_{D}=0 \mathrm{~d}$, and (b) the density-dependent model with $r_{D}=10 \mathrm{~d}^{-1}$ and $\tau_{D}=1 \mathrm{~d}$. 
half of its initial value $\left(p \rightarrow \frac{p}{2}\right.$ when $\left.F=\mathrm{IC}_{50}\right)$. Other models such as: Saenz et al., Hancioglu et al., and Bocharov et al. incorporate IFN effect as causing target cells to become resistant to infection $[12,30,67]$. Our approach, however, is simpler and similar to that adopted by Handel et al. and Baccam et al. who incorporate IFN effect by down-regulating production [2,32], where Baccam et al., in addition to down-regulating production also lengthen the duration of the eclipse phase [2]. Addition of the effect of IFN to the model does not require a new solution to the equations. It is sufficient to allow the viral production rate, $p$, to be time dependent since $F$ is time dependent.

The effect of IFN in the presented model is shown in Fig. 6.2. Viral titer peak is reduced due to $\mathrm{IFN}$ presence with smaller $\mathrm{IC}_{50}$, having a greater impact on the viral titer peak. However, once IFN starts to decay its effect rapidly disappears and the new target cells, that have replaced the dead cells, become infected by virus and rekindle the infection. This is translated into a rise in the viral titer in the absence of specific immune response as predicted by Hancioglu et al. [30]. Previous studies that couple modelling of IFN and in-host viral titer data suggest that peak viral load reduction and sparing of epithelial cells correlates with increasing IFN efficiency [67].

Upon investigation of the effect of the time of IFN peak in Fig. 6.3 shows that an early action of IFN delays viral titer peak such as for $t_{p}=1-2 \mathrm{~d}$. On the other hand, if IFN peaks later, i. e. on 3-4 dpi, a reduced primary peak is observed with temporary viral decay followed by titer rebound. As can be seen in Fig. 6.1, most experimental measurements of IFN time course predict a peak between 2-3 dpi, a peak at 5 dpi was also reported by Iwasaki et al., 1977 [41]. Mathematical models, however, predict an IFN peak that can arise almost immediately after infection till 3 dpi. Prior to IFN peak, it has an increasing effect on the viral production. IFN effect is maximum at its peak and $p \rightarrow \frac{p}{2}$, hence its time of peak corresponds to an anticlimax in the viral titer. The innate immune response in our model impedes viral production during the first $1-4$ days post infection rendering infection less severe at early times. However, it does not lead to infection resolution which is therefore left up to the adaptive immune response.

\subsection{Antibodies}

Several experiments measure the antibody titers over time. It is noteworthy to mention that $\mathrm{Ab}$ levels measurements in blood can only detect the free $\mathrm{Ab}$ and whatever $\mathrm{Ab}$ have formed immune complexes with an antigen will not be counted. Hence, released $\mathrm{Ab}$ levels are probably higher than what is measured, particularly early post infection. Mathematical models of influenza also incorporate $\mathrm{Ab}$ into their kinetics and predict 

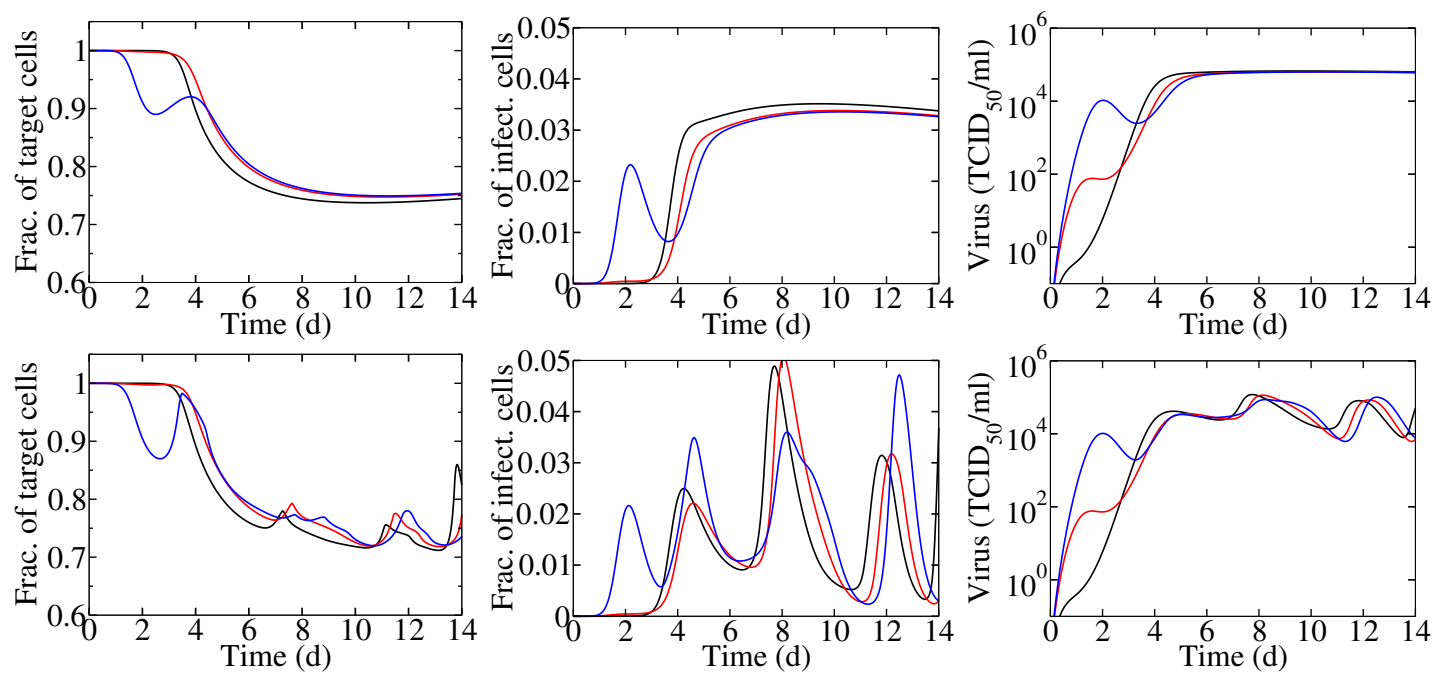

Figure 6.3: The effect of changing the time of IFN peak on infection kinetics. The panels from left to right represent fraction of target cells, fraction of infectious cells and viral titer. In the top row, infection kinetics are demonstrated in the densityindependent model at $r_{D}=1 \mathrm{~d}^{-1}, \tau_{D}=0 \mathrm{~d}$ and $\mathrm{IC}_{50}=10$. In the bottom row, infection kinetics are demonstrated in the density-dependent model at $r_{D T}=10 \mathrm{~d}^{-1}, \tau_{D}=1 \mathrm{~d}$ and $\mathrm{IC}_{50}=10$. Interferon peaks at day 1 post infection (black), day 2 post infection (red), and day 3 post infection (blue). 

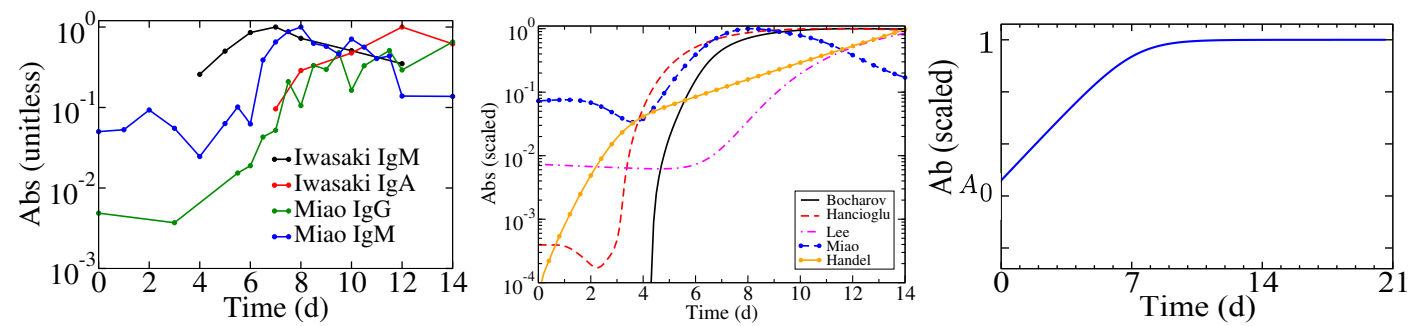

Figure 6.4: The time courses of $\mathbf{A b}$. The left panel shows experimental titers of Abs in mice. The center panel shows influenza modelling predictions of Ab time course during the infection. The right panel shows the Ab time course as simulated in this project. The modelled $\mathrm{Ab}$ time course here grows at $\alpha=1.36 \mathrm{~d}^{-1}$.

their time course. In general, Abs are known to grow into elevated levels after infection and peak at around $7 \mathrm{dpi}$. In this project, the amount of antibodies is modelled to be spatially homogeneous (independent of $x$ ) at any given time, $t$, as:

$$
A(t)=\frac{1}{1+\left(\frac{1}{A_{0}}-1\right) e^{-\alpha t}},
$$

where $A_{0}$ is the initial amount of antibodies, and $\alpha$ is the growth rate of antibodies $\left(\mathrm{d}^{-1}\right)$ and it is set in our simulations so that $\mathrm{Ab}$ reach $99 \%$ of their maximum concentration at $7 \mathrm{dpi}$, the $\mathrm{Ab}$ time course as measured by experiments and predicted by models, including this project, is shown in Fig. 6.4

Antibodies form immune complexes with the virus that reduce the number of free virions capable of infecting target cells [76]. Contrary to the case of IFN, where there is a large variation in the mode of implementation, most mathematical models of influenza implement antibodies as a clearance term in the virus equation. Similarly to the approach adopted by $[12,30,31,47,53]$, we model this effect as an additional clearance term in the virus kinetics shown in Eq. (2.1):

$$
c \rightarrow c+k_{v} A(t)
$$

where $k_{v}$ is the binding affinity of antibodies at saturation $\left(\mathrm{d}^{-1}\right)$. Modelling the effect of antibodies does not require re-solving the virus equation. We implement their action by incorporating the additional clearance term, $k_{v} A(t)$, to the clearance, $c$.

As can be seen in Fig. 6.6, low binding affinity $\operatorname{Abs}\left(k_{v}=10^{3} \mathrm{~d}^{-1}\right)$ are not capable of clearing the infection. When $k_{v}$ increases from $2 \times 10^{3} \mathrm{~d}^{-1}$ to $5 \times 10^{4} \mathrm{~d}^{-1}$ viral titer decay rate increases leading to viral titer decay within 10-21 d. Previous estimates of 
Table 6.1: Estimates of antibody clearance in mathematical models*.

\begin{tabular}{lccc}
\hline \hline Model & $k$ & $\mathrm{Ab}_{m}$ & $k_{v}$ \\
\hline Bocharov et al., 1994 & $8.6 \times 10^{11} \mathrm{~mol}^{-1} \mathrm{~d}^{-1}$ & $8.5 \times 10^{-13} \mathrm{~mol}$ & $0.73 \mathrm{~d}^{-1}$ \\
Hancioglu et al., 2007 & $619.2 \mathrm{~mol}^{-1} \mathrm{~d}^{-1}$ & $7.2 \times 10^{-11} \mathrm{~mol}$ & $36 \times 10^{-9} \mathrm{~d}^{-1}$ \\
Lee et al., 2009 & $4 \times 10^{-3} \mathrm{titer}^{-1} \mathrm{~d}^{-1}$ & $3 \times 10^{4} \mathrm{titer}$ & $120 \mathrm{~d}^{-1}$ \\
Miao et al., 2010 & $7.8 \times 10^{-2} \mathrm{~mL} \cdot \mathrm{pg}^{-1} \cdot \mathrm{d}^{-1}$ & $4 \times 10^{2} \mathrm{pg} \cdot \mathrm{mL}^{-1}$ & $31.2 \mathrm{~d}^{-1}$ \\
Handel et al., 2010 & $1.8 \mathrm{titer}^{-1} \mathrm{~d}^{-1}$ & $21 \times 10^{5} \mathrm{titer}$ & $38 \times 10^{5} \mathrm{~d}^{-1}$ \\
\hline \hline
\end{tabular}

${ }^{*}$ The clearance term in all these studies is identical to this model $(-k V A)$ where $k$ is the binding affinity between virus and antibodies, $\mathrm{Ab}_{m}$ is the amount of antibodies at saturation, and $k_{v}=k \times \mathrm{Ab}_{m}$. The exception is in the model proposed by Handel et al., 2010 who introduced an "antigenic distance" variable, $\mathrm{S}$, as $-k S V A . \mathrm{S}=0.8$ at maximum compatibility between virus and antibodies. The values presented are best fit parameters in the presence of innate immune response extracted from the papers that present them $[12,30,31,47,53]$.
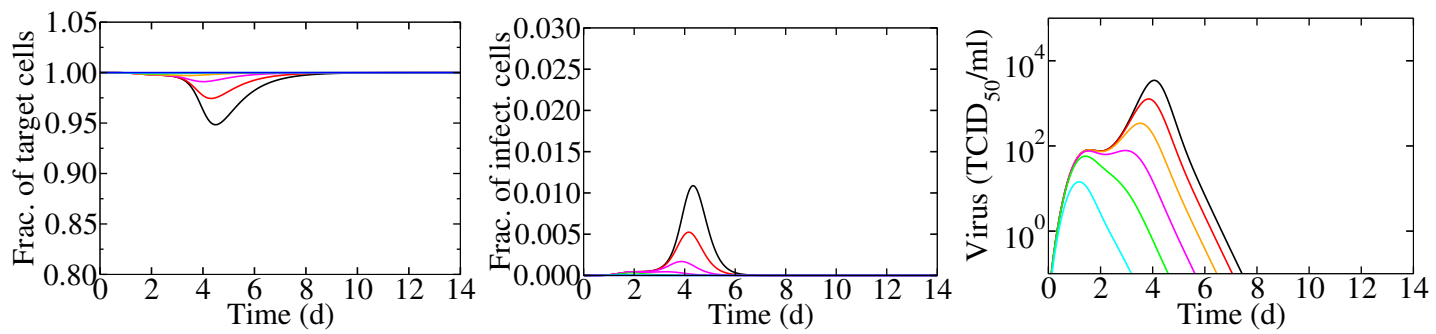

Figure 6.5: The effect of initial $\mathrm{Ab}$ abundance on the infection kinetics. The $\mathrm{Ab}$ exponential growth rate, $\alpha$ is set so that $A(7)=0.99$. Kinetics are shown in the density-independent model with $r_{D}=1 \mathrm{~d}^{-1}, \tau_{D}=0 \mathrm{~d}$ and $k_{v}=10^{4} \mathrm{~d}^{-1}$. The initial antibody amount varies from $10^{-8}$ to $10^{-2}$ in steps of one order of magnitude starting with the black line up to the blue line.

the binding affinity between virus and antibodies vary widely between $10^{-8}-10^{6} \mathrm{~d}^{-1}$ as shown in Table 6.1. Viral clearance is accompanied by target cell recovery and loss of infectious cells. Antibodies with a binding affinity sufficient for infection clearance, $k_{v}=2 \times 10^{3} \mathrm{~d}^{-1}$, do so more effectively if they are present in abundance at the beginning of the infection (i.e. $\left.A_{0} \geq 0.001\right)$ possibly due to an earlier encounter with the virus as shown in Fig. 6.5.

In order to evaluate the relative importance of initial $\mathrm{Ab}$ amount as compared to $\mathrm{Ab}$ binding affinity, both parameters are varied and the results are shown in Fig. 6.7. Starting with an elevated amount of $\mathrm{Ab}\left(10^{-2}\right)$ with low binding affinity represented by $k_{v}=10^{3} \mathrm{~d}^{-1}$ does not lead to protection against infection as illustrated in Fig. 6.7. Starting with an initial amount of antibodies of $10^{-5}$ with binding affinity of $10^{4} \mathrm{~d}^{-1}$ 

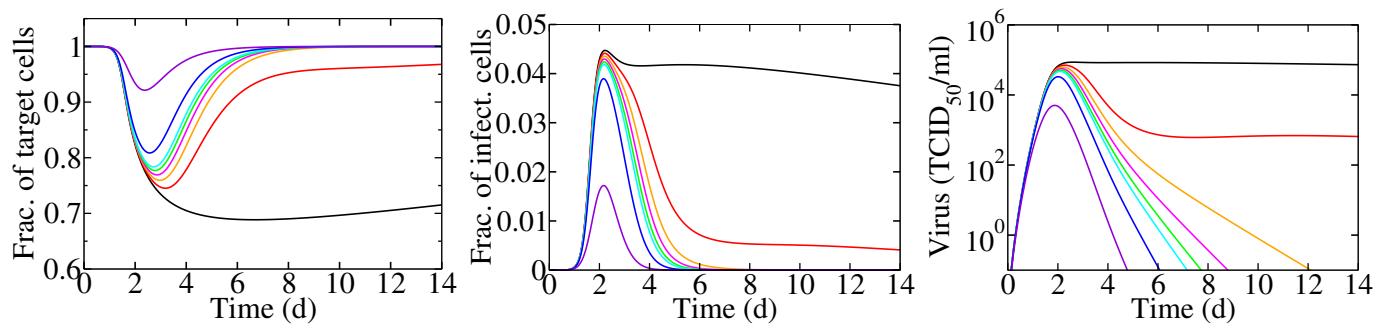

(a)
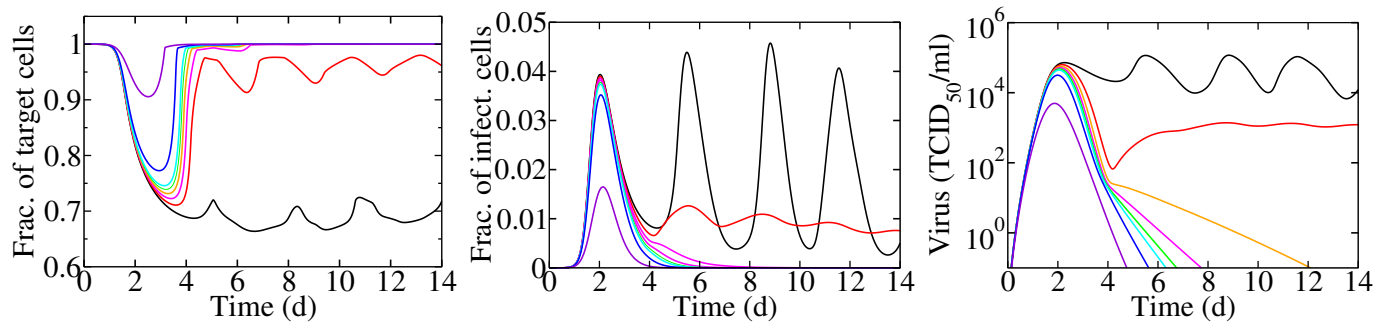

(b)

Figure 6.6: The effect of $\mathrm{Ab}$ on the infection kinetics. The $\mathrm{Ab}$ exponential growth rate is $1 \mathrm{~d}^{-1}$ and $A b_{0}=10^{-4}$, the binding efficiency of $\mathrm{Abs}$ is $10^{3}, 2 \times 10^{3}, 3 \times 10^{3}, 4 \times 10^{3}, 5 \times 10^{3}, 10^{4}, 5 \times 10^{4} \mathrm{~d}^{-1}$ for colours starting with red and ending in blue. The black line corresponds to absence of Ab. Kinetics are shown in: (a) the density-independent model with $r_{D}=1 \mathrm{~d}^{-1}$ and $\tau_{D}=0 \mathrm{~d}$, (b) the density-dependent model with $r_{D T}=10 \mathrm{~d}^{-1}$ and $\tau_{D}=1 \mathrm{~d}$. 


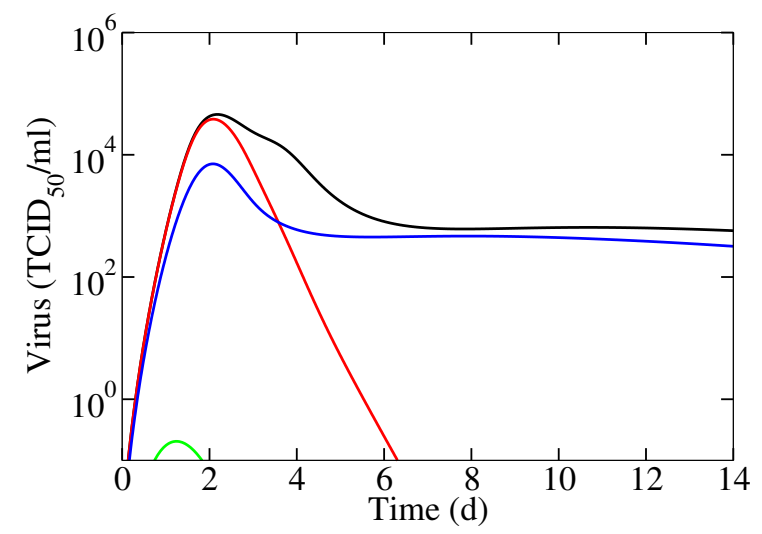

Figure 6.7: Exploring the effect of preexisting immunity on the infection kinetics. Two parameters are varied: $A b_{0}$ and $k_{v}$. colour legend as follows: $A b_{0}=0.1$ (black), $k_{v}=10^{3} \mathrm{~d}^{-1}, A b_{0}=0.1, k_{v}=10^{4} \mathrm{~d}^{-1}$ (red), $A b_{0}=100, k_{v}=10^{3} \mathrm{~d}^{-1}$ (blue), and $A b_{0}=100, k_{v}=10^{4} \mathrm{~d}^{-1}$ (green). IFN peaks at day 3 and is characterized by an $\mathrm{IC}_{50}=50$.

could not resolve the infection. However, when $k_{v}$ increased to $10^{4} \mathrm{~d}^{-1}$ and starting with $A b_{0}=10^{-2}$ infection was completely suppressed.

\subsection{Reproducing the three infection profiles}

Chronic infections have been established by virtue of cellular regeneration. Furthermore, infection can be successfully resolved due to adaptive immunity. It remains to establish that the resolved infection can take a seasonal or severe form. In the presented model, the type of the infection is determined by the immune response as can be seen in Fig. 6.8. In the absence of any immunity, the infection takes a chronic form. When immune response is present, the infection takes a severe form for low binding affinity Abs $\left(k_{v}=10^{3} \mathrm{~d}^{-1}\right)$ that is characterized by an elevated viral titer for more that $14 \mathrm{dpi}$, or a seasonal form for Abs with a 50 fold greater binding affinity $\left(k_{v}=5 \times 10^{4} \mathrm{~d}^{-1}\right)$ that is resolved within 8 dpi. This is a minor parameter change that behaves consistently with known biology.

The maximum fraction of dead cells for all $\mathrm{Ab}$ binding affinities, and in the absence of antibodies as well, is $\approx 30 \%$ which is in agreement with the general picture drawn by Bocharov et al.,1994, based on studies of Marchuk et al., 1989 [12,48]. According to the general picture mentioned, cell death of around $10 \%$ leads to the onset of symptoms and subsequently, may accompany disease resolution. Thus, symptomatic infection duration in our model is between 3-6 dpi for a seasonal infection, and between 2-11 dpi for a 

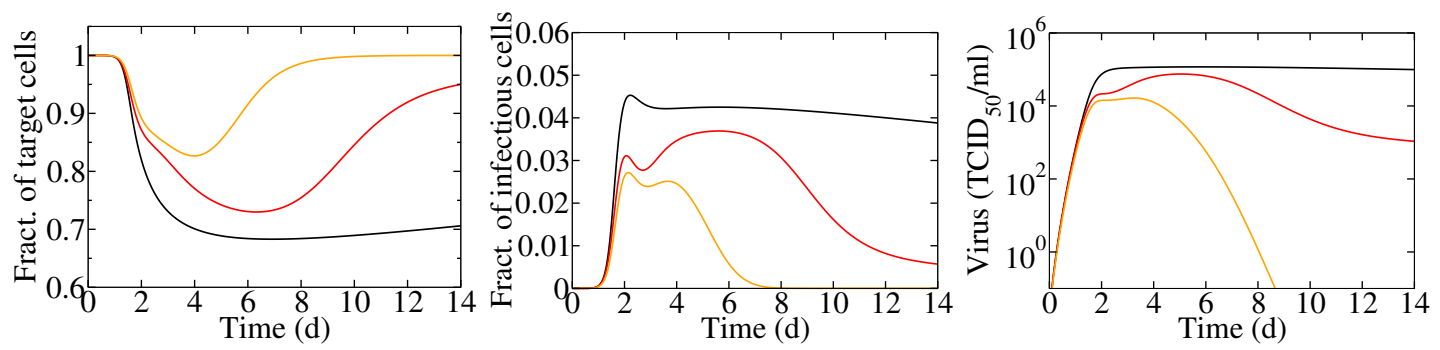

Figure 6.8: The three infection profiles observed in patients. Chronic infection (black) is obtained in the absence of an immune response. Severe infection (red) is obtained when $k_{v}=10^{3} \mathrm{~d}^{-1}$, and a seasonal infection (orange) occurs for $k_{v}=5 \times 10^{4} \mathrm{~d}^{-1}$. In seasonal and severe infections, interferon have an $\mathrm{IC}_{50}=50$ and peak at $2 \mathrm{dpi}$, the initial amount of antibodies is 0.001 . It is noteworthy that changing the antibody binding affinity is sufficient to change infection profile from seasonal to severe.

severe infection. 


\section{Chapter 7}

\section{Discussion}

Influenza infections are most frequently modelled with ODEs that do not incorporate any spatial effects and have implicit assumptions of spatial uniformity that are not realistic. Within the human RT, virus infects present in the PCF infects epithelial cells. While in this fluid, virus particles are free to diffuse isotropically and the entire bulk of the PCF advects upwards, towards the top of the RT, due to entrainment by mucus. Motivated by the lack of a spatial model that incorporates viral advection and diffusion, a PDE model was developed. The RT was modelled as a one-dimensional tract that extends up to a depth of $0.3 \mathrm{~m}$. The advantage of this spatial model is that it allows us to evaluate their effect on infection kinetics.

As compared to the infinite diffusion ODE models, a biologically realistic diffusion of $10^{-12} \mathrm{~m}^{2} \cdot \mathrm{s}^{-1}$ leads to a very slowly progressing infection. Virus advection due to entrainment by the mucus blanket, on the other hand, results in a fast elimination of virus from the RT. It therefore provides a very effective defense mechanism against viral infection besides the attachment of virions to mucus. In fact, in the presence of upwards entrainment of the PCF, we found that a virus production rate around 11 times larger than previously evaluated by Baccam et al. [2], is needed for infection to embark while ensuring that the infection peaks at $2 \mathrm{dpi}$.

Interestingly, site of deposition of the cough droplet carrying influenza virions played a major role in determining the extent of RT involvement in the infection as no target cell consumption is observed below that initial depth of deposition. The depth of initial viral inoculum deposition plays an important role in shaping the infection. The deeper the viral deposition the larger the involvement of RT in the infection. Steady state kinetics are reached faster when depositing deeper. Deposition at the top of the RT $\left(x_{d}=0.01 \mathrm{~m}\right)$ does not result in the development of infection as virus is swept out before 
it has any chance to infect cells. Despite the depth at which virus was deposited in the RT, infection starts at the very top of the RT due to the combined effect of the swept virus from the initial pulse traversing the RT, and the small amount of virus produced by secondary infections due to the initial pulse. Perhaps this would not be the case if cell-to-cell infection contributed to infection.

Cellular regeneration allowed the establishment of chronic infections. The densitydependent and density-independent models overall resulted in similar kinetics, except for the case of density-dependent model and a delay of $1 \mathrm{~d}$. In this particular case non-smooth kinetics were observed where regeneration was driven by cell death but also limited by the abundance of target cells left. Hence, alternating periods of active regeneration and idleness were observed. While known biology does not allow the discrimination of either model, these models gave us an insight into the possible kinetics resulting from this biological process.

We modelled immunity via two main components: the innate response via interferon, and the adaptive response via antibodies. Under the assumption that interferon acts early during the infection by impeding viral replication, IFN reduced disease severity, as manifested by decreased viral titer and less cell death, at early times only. The fact that interferon effect declines at early times is due to modelling its concentration with a triangular function. Interferon alone, however, is not sufficient to terminate infection at all efficiencies and antibodies are necessary for the infection to be resolved. The initial amount of antibodies and their binding efficiency to the antigen (virus) determines how fast and how efficiently the infection will be stopped. Depending on antibody binding efficiency, an infection can either take a seasonal, or a severe form. A chronic infection develops in the absence of antibodies.

One of the limitations of this model is the assumed uniform cell density through the respiratory tract. Unfortunately, available quantitative data on cell numbers in different regions of the respiratory tract and their type, is insufficient to permit construction of an accurate model to realistically represent a depth-varying cell density. Another assumption in the model is that mucus speed, and the entrained periciliary fluid speed as well, does not vary as a function of depth in the respiratory tract, although, particles deposited in peripheral bronchiolar airways clear more slowly than those in more central airways [1]. Future development of this model to address these issues may provide new insights into spatial in-host influenza infection kinetics.

The simplified geometry assumed for the RT can be useful in shedding light on other biological mechanisms. Validation against patient data, however, would be challenging due to the limited data and long simulation time. The effect of viral transport modes was 
evaluated for the first time and found to play a critical role in protecting the lower RT against infection propagation. While computational modelling of infectious disease has proved to be useful in characterizing the disease and optimizing antiviral treatments, it is very important not to over-complicate and over-parametrize the model with parameters that are not directly measured and therefore would introduce and propagate imprecision and error. Our model has the advantage of being able to capture the different types of infection while retaining its simplicity and capability for further development and validation against experimental data when available.

As a conclusion, it was found that the mucus affords a great protection to the respiratory tract, and the viral production rate is underestimated when not accounting for advection. It was also shown that the depth of virus deposition is a possible contributor to infection severity and may also have contribution in the determination of cell tropism. Furthermore, an infection can possibly be chronically sustained by the virtue of cellular regeneration in the absence of an immune response of antiviral therapy. A simplified immune response in this model is capable of explaining the discrimination between severe and uncomplicated (seasonal) infections. 


\section{Bibliography}

[1] B. Asgharian, W. Hofmann, and F. Miller. Mucociliary clearance of insoluble particles from the tracheobronchial airways of the human lung. Aerosol Science, $32(6): 817-832,2001$.

[2] P. Baccam, C. Beauchemin, C. A. Macken, F. G. Hayden, and A. S. Perelson. Kinetics of influenza A virus infection in humans. J. Virol., 80(15):7590-7599, 2006.

[3] S. Baos, D. Phillips, L. Wildling, T. McMaster, and M. Berry. Distribution of sialic acids on mucins and gels: a defense mechanism. J. Biophys, 102(1):176-184, 2012.

[4] A. L. Bauer, C. A. A. Beauchemin, and A. S. Perelson. Agent-based modeling of host-pathogen systems: The successes and challenges. Inform. Sciences, 179(10):1379-1389, 2009.

[5] C. Beauchemin. Spatiotemporal Modelling of Viral Infection Dynamics. PhD thesis, University of Alberta, 2005.

[6] C. Beauchemin. Probing the effects of the well-mixed assumption on viral infection dynamics. J. Theor. Biol., 242(2):464-477, 2006.

[7] C. Beauchemin, N. Dixit, and A. S. Perelson. Characterizing T cell movement within lymph nodes in the absence of antigen. J. Immunol., 178(9):5505-5512, 2007.

[8] C. Beauchemin, S. Forrest, and F. T. Koster. Modeling influenza viral dynamics in tissue. In H. Bersini and J. Carneiro, editors, Proceedings of the $5^{\text {th }}$ International Conference on Artificial Immune Systems (ICARIS 06), pages 23-36. SpringerVerlag Berlin Heidelberg, 2006.

[9] C. Beauchemin, J. Samuel, and J. Tuszynski. A simple cellular automaton model for influenza A viral infections. J. Theor. Biol., 232(2):223-234, 2005. 
[10] C. A. A. Beauchemin and A. Handel. A review of mathematical models of influenza a infections within a host or cell culture: lessons learned and challenges ahead. $B M C$ Public Health, 11(Suppl 1):S1-S7, 2011.

[11] J. Blake. On the movement of mucus in the lung. J. Biomechanics, 8(3-4):179-190, 1975.

[12] G. A. Bocharov and A. A. Romanyukha. Mathematical model of antiviral immune response III. Influenza A virus infection. J. Theor. Biol., 167(4):323-360, 1994.

[13] G. Boivin, N. Goyette, and H. Bernatchez. Prolonged excretion of amantadineresistant influenza A virus quasi species after cessation of antiviral therapy in an immunocompromised patient. Clin. Infect. Dis., 34(5):e23-e25, 2002.

[14] M. Chan, R. Chan, W. Yu, C. Ho, W. Chiu, K. Yuen, Y. Guan, J. Nicholls, and M. Peiris. Influenza H5N1 virus infection of polarized human alveolar epithelial cells and lung microvascular endothelial cells. Respir. Res., 10(1):102-114, 2009.

[15] C. Coraux, R. Hajj, P. Lesimple, and E. Puchelle. In vivo models of human airway epithelium repair and regeneration. Eur. Respir. Rev., 14(97):131-136, 2005.

[16] J. D. Crapo, B. Barry, P. Gehr, M. Bachofen, and E. Weibel. Cell number and cell characteristics of the normal human lung. Am. Rev. Respir. Dis., 125(2):332-337, 1982.

[17] L. M. Crosby and C. M. Waters. Epithelial repair mechanisms in the lung. Am. J. Physiol. Lung Cell. Mol. Physiol., 198(6):L715-L731, 2010.

[18] R. G. Crystal and J. B. West. The Lung: Scientific Foundations, volume 1. Raven Press Ltd., New York, USA, second edition, 1991.

[19] H. Dahari, A. Lo, R. M. Ribeiro, and A. S. Perelson. Modeling hepatitis C virus dynamics: Liver regeneration and critical drug efficacy. J. Theor. Biol., 247(2):371$381,2007$.

[20] N. Dixit, J. Layden-Almer, T. Layden, and A. Perelson. Modelling how ribavirin improves interferon response rates in hepatitis $\mathrm{C}$ virus infection. Nature, 432(7019):922-924, 2004.

[21] H. M. Dobrovolny, M. J. Baron, R. Gieschke, B. E. Davies, N. L. Jumbe, and C. A. A. Beauchemin. Exploring cell tropism as a possible contributor to influenza infection severity. PLoS One, 5(11):e13811-e13826, 2010. 
[22] H. M. Dobrovolny, G. Boivin, A. S. Perelson, and C. A. A. Beauchemin. Modelling the emergence of influenza drug resistance under various drug therapies. 2012. In preparation.

[23] H. M. Dobrovolny, R. Gieschke, B. E. Davies, N. L. Jumbe, and C. A. A. Beauchemin. Neuraminidase inhibitors for treatment of human and avian strain influenza: A comparative study. J. Theor. Biol., 269(1):234-244, 2011.

[24] H. M. Dobrovolny, M. B. Reddy, M. A. Kamal, C. R. Rayner, and C. A. A. Beauchemin. A review of our current understanding of the immune response against influenza and the additional insights provided by mathematical models. 2012. In preparation.

[25] P. Fabian, J. J. McDevitt, W. H. DeHaan, R. O. P. Fung, B. J. Cowling, K. H. Chan, G. M. Leung, and D. K. Milton. Influenza virus in human exhaled breath: An observational study. PLoS One, 3(7):e2691-e2697, 2008.

[26] R. S. Fritz, F. G. Hayden, D. P. Calfee, L. M. R. Cass, A. W. Peng, W. G. Alvord, W. Strober, and S. E. Straus. Nasal cytokine and chemokine response in experimental influenza A virus infection: Results of a placebo-controlled trial of intravenous zanamivir treatment. J. Infect. Dis., 180(3):586-593, 1999.

[27] A. F. Gazdar, R. I. Linnoila, Y. Kurita, H. K. Oie, J. L. Mulshine, J. C. Clark, and J. A. Whitsett. Peripheral airway cell differentiation in human lung cancer cell lines. Cancer Res., 50(17):5481-5487, 1990.

[28] R. A. Goldsby, T. J. Kindt, and B. A. Osborne. Kuby Immunology $6^{\text {th }}$ Edition. W. H. Freeman and Company, New York, 2006.

[29] R. A. Guilmette, Y. S. Cheng, and W. C. Griffith. Characterising the variability in adult human nasal airway dimensions. Ann. Occup. Hyg., 41(Supplement 1):491496, 1997.

[30] B. Hancioglu, D. Swigon, and G. Clermont. A dynamical model of human immune response to influenza A virus infection. J. Theor. Biol., 246(1):70-86, 2010.

[31] A. Handel, I. M. Longini, and R. Antia. Towards a quantitative understanding of the within-host dynamics of influenza A infections. J. R. Soc. Interface, 7(42):35-47, 2010 . 
[32] A. Handel, I. M. J. Longini, and R. Antia. Neuraminidase inhibitor resistance in influenza: Assessing the danger of its generation and spread. PLoS Comput. Biol., $3(12): 2456-2464,2007$.

[33] F. G. Hayden, R. S. Fritz, M. C. Lobo, W. G. Alvord, W. Strober, and S. E. Straus. Local and systemic cytokine responses during experimental human influenza A virus infection. J Clin. Invest., 101(3):643-649, 1998.

[34] A. Heguy, B. Harvey, P. L. Leopold, I. Dolgalev, T. Raman, and R. G. Crystal. Responses of the human airway epithelium transcriptome to in vivo injury. Physiol. Genomics, 29(2):139-148, 2007.

[35] D. Ho, A. U. Neumann, A. S. Perelson, W. Chen, J. M. Leonard, and M. Markowitz. Rapid turnover of plasma virions and CD4 lymphocytes in HIV-1 infection. Nature, 373(6510):123-126, 1995.

[36] W. Hofmann. Modelling inhaled particle deposition in the human lung-A review. Aerosol Science, 42(10):693-724, 2011.

[37] B. P. Holder, L. E. Liao, P. Simon, G. Boivin, and C. A. A. Beauchemin. Design considerations in building in silico equivalents of common experimental influenza virus assays and the benefits of such an approach. Autoimmunity, 44(4):282-293, 2011.

[38] B. P. Holder, P. Simon, L. E. Liao, Y. Abed, X. Bouhy, C. A. A. Beauchemin, and G. Boivin. Assessing the in vitro fitness of an oseltamivir-resistant seasonal A/H1N1 influenza strain using a mathematical model. PLoS One, 6(3):e14767-e14778, 2011.

[39] A. Hoshino, H. Takenaka, O. Mizukoshi, J. Imanishi, T. Kishida, and M. G. Tovey. Effect of anti-interferon serum of influenza virus infection in mice. Antiviral Res., 3(1):59-65, 1983.

[40] ICRP. Report of the task group on reference man. Technical report, International Commission on Radiological Protection, 1975.

[41] T. Iwasaki and T. Nozima. The roles of interferon and neutralizing antibodies and thymus dependence of interferon and antibody production. J. Immunol, 118(1):256263, 1977.

[42] P. D. Jones and G. L. Ada. Influenza virus-specific antibody-secreting cells in the murine lung during primary influenza virus infection. J. Virol., 60(2):614-619, 1986. 
[43] L. Kaiser, R. S. Fritz, S. E. Straus, L. Gubareva, and F. G. Hayden. Symptom pathogenesis during acute influenza: interleukin- 6 and other cytokine responses. $J$. Med. Virol., 64(3):262-268, 2001.

[44] E. D. Kilbourne. Influenza. Plenum Medical Book Company, New York, 1987.

[45] A. I. Klimov, E. Rocha, F. G. Hayden, P. A. Shult, L. F. Roumillat, and N. J. Cox. Prolonged shedding of amantadine-resistant influenza A viruses by immunodeficient patients: Detection by polymerase chain reaction-restriction analysis. J. Infect. Dis., 172(5):1352-1355, 1995.

[46] T. Kuiken and J. K. Taubenberger. Pathology of human influenza revisited. Vaccine, 26S(Suppl 4):D59-D66, 2008.

[47] H. Y. Lee, D. J. Topham, S. Y. Park, J. Hollenbaugh, J. Treanor, T. R. Mosmann, X. Jin, B. M. Ward, H. Miao, J. Holden-Wiltse, A. S. Perelson, M. Zand, and H. Wu. Simulation and prediction of the adaptive immune response to influenza A virus infection. J. Virol., 83(14):7151-7165, July 2009.

[48] G. I. Marchuk and A. P. Berbentzova. Acute pneumonia: immunology, severity estimation, clinics and treatment. Nauka, Moscow, 1989.

[49] M. N. Matrosovich, T. Y. Matrosovich, T. Gray, N. A. Roberts, and H.-D. Klenk. Human and avian influenza viruses target different cell types in cultures of human airway epithelium. P. Natl. Acad. Sci. USA, 101(13):4620-4624, 2004.

[50] M. N. Matrosovich, T. Y. Matrosovich, J. Uhlendorff, W. Garten, and H.-D. Klenk. Avian-virus-like receptor specificity of the hemagglutinin impedes influenza virus replication in cultures of human airway epithelium. Virology, 361(2):384-390, 2007.

[51] H. Matsui, S. H. Randell, S. W. Peretti, C. W. Davis, and R. C. Boucher. Coordinated clearance of periciliary liquid and mucus from airway surfaces. J. Clin. Invest., 102(6):1125-1131, 1998.

[52] R. Mercer, M. Russel, V. Roggli, and J. Crapo. Cell number and distribution in human and rat airways. Am. J. Respir. Cell Mol. Biol., 10(6):613-624, 1994.

[53] H. Miao, J. A. Hollenbaugh, M. S. Zand, J. Holden-Wiltse, T. R. Mosmann, A. S. Perelson, H. Wu, and D. J. Topham. Quantifying the early immune response and adaptive immune response kinetics in mice infected with influenza A virus. J. Virol., 84(13):6687-6698, 2010. 
[54] R. Mora, E. Rodriguez-Boulan, P. Palese, and A. García-Sastre. Apical budding of a recombinant influenza A virus expressing a hemagglutinin protein with a basolateral localization signal. J. Virol., 76(7):3544-3553, 2002.

[55] A. U. Neumann, N. P. Lam, H. Dahari, M. Davidian, T. E. Wiley, A. P. B. Mika, and T. J. Layden. Differences in viral dynamics between genotypes 1 and 2 of hepatitis C virus. J. Infect. Dis., 182(1):28-35, 2000.

[56] A. U. Neumann, N. P. Lam, H. Dahari, D. R. Gretch, T. E. Wiley, T. J. Layden, and A. S. Perelson. Hepatitis $\mathrm{C}$ viral dynamics in vivo and the antiviral efficacy of interferon-alpha therapy. Science, 282(5386):103-107, 1998.

[57] J. Nicholls, M. Chan, W. Chan, H. Wong, C. Cheung, D. Kwong, M. Wong, W. Chui, L. L. M. Poon, S. Tsao, Y.Guan, and J. Peiris. Tropism of avian influenza A H5N1 in the upper and lower respiratory tract. Nat. Med., 13(2):147-149, 2007.

[58] S. Park and A. Wexler. Size-dependent deposition of particles in the human lung at steady-state breathing. Aerosol Science, 39(3):266-276, 2008.

[59] A. S. Perelson, P. Essunger, Y. Cao, M. Vesanen, A. Hurley, K. Saksela, M. Markowitz, and D. D. Ho. Decay characteristics of HIV-1 infected compartments during combination therapy. Nature, 387(6629):188-191, 1997.

[60] A. S. Perelson, A. Neumann, M. Markowitz, J. Leonard, and D. Ho. HIV-1 dynamics in vivo: Virion clearance rate, infected cell life-span, and viral generation time. Science, 271(5255):1582-1586, 1996.

[61] B. A. Pinsky, S. Mix, J. Rowe, S. Ikemoto, and E. J. Baron. Long-term shedding of influenza A virus in stool of immunocompromised child. Emerg. Infect. Dis., 16(7):1165-1167, 2010.

[62] C. W. Potter. Influenza. In A. J. Zuckerman, J. E. Banatvala, J. R. Pattison, P. D. Griffiths, and B. D. Schoub, editors, Principles and Practice of Clinical Virology, chapter 5, pages 271-297. John Wiley \& Sons, Ltd., 5th edition, 2004.

[63] O. Raabe, H. Yeh, G. Schum, and R. F. Phalen. Tracheobronchial Geometry: Human, Dog, Rat, Hamster. Lovelace Foundation, Albuquerque, New Mexico, 1976.

[64] T. C. Reluga, H. Dahari, and A. S. Perelson. Analysis of hepatitis C virus infection models with hepatocyte homeostasis. SIAM J. Appl. Math., 69(4):999-1023, 2009. 
[65] C. Renaud, A. A. Boudreault, J. Kuypers, K. H. Lofy, L. Corey, M. J. Boeckh, and J. A. Englund. H275Y mutant pandemic (H1N1) 2009 virus in immunocompromised patients. Emerg. Infect. Dis., 17(4):653-660, 2011.

[66] N. J. Roberts, R. Douglas, R. M. Simons, and M. E. Diamond. Virus-induced interferon production by human macrophages. J. Immunol., 123(1):365-369, 1979.

[67] R. A. Saenz, M. Quinlivan, D. Elton, S. MacRae, A. S. Blunden, J. A. Mumford, J. M. Daly, P. Digard, A. Cullinane, B. T. Grenfell, J. W. McCauley, J. L. N. Wood, and J. R. Gog. Dynamics of influenza virus infection and pathology. J. Virol., 84(8):3974-3983, 2010.

[68] S. H. Seo and R. G. Webster. Tumor necrosis factor alpha exerts powerful antiinfluenza virus effects in lung epithelial cells. J. Virol., 76(3):1071-1076, 2002.

[69] S. Serafini and E. Michaelson. Length and distribution of cilia in human and canine airways. Bull. Eur. Physiopathol. Respir., 13(4):551-559, 1977.

[70] M. A. Sleigh, J. R. Blake, and N. Liron. The propulsion of mucus by cilia. Am. Rev. Respir. Dis, 137(3):726-741, 1988.

[71] E. Snoeck, P. Chanu, M. Lavielle, P. Jacqmin, E. N. Jonsson, K. Jorga, T. Goggin, J. Grippo, N. L. Jumbe, and N. Frey. A comprehensive hepatitis C viral kinetic model explaining cure. Clin. Pharmacol. Ther., 87(6):706-713, 2010.

[72] G. R. Stark, I. M. Kerr, B. R. Williams, R. H. Silverman, and R. D. Schreiber. How cells respond to interferons. Annu. Rev. Biochem., 67(1):227-264, 1998.

[73] K. C. Stone, R. R. Mercer, B. A. Freeman, L. Y. Chang, and J. D. Crapo. Distribution of lung cell numbers and volumes between alveolar and nonalveolar tissue. Am. Rev. Respir. Dis., 146(2):454-456, 1992.

[74] M. D. Stoneham. The nasopharyngeal airway, assessment of position by fibreoptic laryngoscopy. Anaesthesia, 48(7):575-580, 1993.

[75] M. C. Strain, D. D. Richman, J. K. Wong, and H. Levine. Spatiotemporal dynamics of HIV propagation. J. Theor. Biol., 218(1):85-96, 2002.

[76] S. Tamura and T. Kurata. Defense mechanisms against influenza virus infection in the respiratory tract mucosa. Jpn. J. Infect. Dis., 57(6):236-247, 2004. 
[77] D. van Riel, V. J. Munster, E. de Wit, G. F. Rimmelzwaan, R. A. Fouchier, A. D. Osterhaus, and T. Kuiken. Human and avian influenza viruses target different cells in the lower respiratory tract of humans and other mammals. Am. J. Pathol., 171(4):1215-1223, 2007.

[78] D. Warburton, L. Perin, R. DeFilippo, S. Bellusci, W. Shi, and B. Driscoll. Stem/progenitor cells in lung development, injury repair, and regeneration. Proc. Am. Thorac. Soc., 5(6):703-706, 2008.

[79] D. M. Weinstock, L. V. Gubareva, and G. Zuccotti. Prolonged shedding of multidrug-resistant influenza A virus in an immunocompromised patient. New Eng. J. Med., 348(9):867-868, 2003.

[80] D. L. Wilhelm. Regeneration of tracheal epithelium. J. Pathol. Bacteriol., 65(2):543-550, 1953.

[81] R. G. Williams and R. Eccles. A new clinical measure of external laryngeal size which predicts the fundamental frequency of the larynx. Acta Otolaryngol. (Stockh.), 110(1-2):141-148, 1990.

[82] J. W. Wong, T. G. Keens, E. M. Wannamaker, D. N. Crozier, H. Levison, and N. Aspin. Effects of gravity on tracheal mucus transport rates in normal subjects and in patients with cystic fibrosis. Pediatrics, 60(2):146-152, 1977.

[83] World Health Organization. Influenza (seasonal). Fact Sheet 211, World Health Organization, Revised March 2009. Available online at: http://www . who.int/mediacentre/factsheets/fs211/.

[84] P. F. Wright and R. G. Webster. Orthomyxoviruses. In D. M. Knipe, P. M. Howley, D. E. Griffin, R. A. Lamb, M. A. Martin, B. Roizman, and S. E. Straus, editors, Fields Virology, volume 1, chapter 47, pages 1533-1579. Lippincott Williams \& Wilkins, fourth edition, 2001.

[85] L. Yao, C. Korteweg, W. Hsueh, and J. Gu. Avian influenza receptor expression in H5N1-infected and noninfected human tissues. FASEB J., 22(3):733-740, 2008.

[86] D. B. Yeates, N. Aspin, H. Levison, M. T. Jones, and A. C. Bryan. Mucociliary tracheal transport rates in man. J. Appl. Physiol., 39(3):487-495, 1975. 


\section{Glossary}

\section{Abbreviations}

Ab Antibody.

dpi Days post-infection.

HCV Hepatitis C virus.

HIV Human immunodeficiency virus.

IFN Interferon.

Ig Immunoglobulin.

ODE Ordinary differential equation.

PCF Periciliary fluid.

PDE Partial differential equation.

RT Respiratory tract.

\section{Variables and parameters}

$A$ Antibody concentration at any time (unitless).

$A_{0}$ Initial concentration of antibodies (unitless).

$\alpha$ Antibody growth rate (units: $\mathrm{d}^{-1}$ ).

$\beta$ Infection rate of cells by virus (units: $\left.\operatorname{TCID}_{50} / \mathrm{mL}\right)^{-1} \cdot \mathrm{d}^{-1}$ ).

$c$ Rate of non-specific viral clearance (units: $\mathrm{d}^{-1}$ ).

$\delta$ Rate of cell death (units: $\mathrm{d}^{-1}$ ). 
$D$ Dead cell (units: cells).

$D_{P C F}$ Diffusion rate (units: $\mathrm{m}^{2} \cdot \mathrm{s}^{-1}$ ).

E Eclipse cell (units: cells).

$F$ Interferon concentration (unitless).

I Infectious cell (unit: cells).

$\mathbf{I C}_{50}$ Inhibitory concentration of interferon (unitless).

$k$ Rate of transition from the eclipse to the infectious state (units: $\mathrm{d}^{-1}$ ).

$k_{v}$ Antibody binding affinity (units: $\mathrm{d}^{-1}$ ).

$\lambda_{d}$ Interferon decay rate (units: $\mathrm{d}^{-1}$ ).

$\lambda_{g}$ Interferon growth rate (units: $\mathrm{d}^{-1}$ ).

$p$ Virus production rate (units: TCID $_{50} / \mathrm{mL} \cdot \mathrm{d}^{-1}$ ).

$r_{D}$ Density-independent target cell regeneration rate (units: $\mathrm{d}^{-1}$ ).

$r_{D T}$ Density-dependent target cell regeneration rate (units: $\mathrm{d}^{-1}$ ).

$T$ Target cell (units: cells).

$t_{p}$ Interferon time of peak (units: $\mathrm{d}$ ).

$\tau_{D}$ Proliferation delay (units: $\mathrm{d}$ ).

$v_{a}$ advection speed (units: $\left.\mathrm{m} \cdot \mathrm{s}^{-1}\right)$.

$V$ Virus (units: TCID $_{50} / \mathrm{mL}$ ).

$x_{d}$ Depth of virus deposition (units: $\mathrm{m}$ ). 